\title{
PROJETO DE UM OTA CMOS POR MEIO DE UM SISTEMA EVOLUCIONÁRIO INTEGRADO AO SPICE
}

\author{
Rodrigo Alves de Lima Moreto*
}

Antonio P. M. Leme*

\author{
Thiago Turcato do Rego*
}

Carlos Eduardo Thomaz ${ }^{*}$

Salvador Pinillos Gimenez

sgimenez@fei.edu.br

* Centro Universitário da FEI

Av. Humberto de Alencar Castelo Branco, 3972

São Bernardo do Campo, São Paulo

\begin{abstract}
OTA Design by Means of an Evolutionary System Integrated to SPICE.

Analog integrated circuits design is a complex task due to the large number of input variables to be determined simultaneously in order to comply with innumerable design features of an analog integrated circuit design. This work describes and implements an evolvable system based on Genetic Algorithms (GA) which was computationally integrated to the simulation program SPICE and has the capability to search for solutions that best comply with the designer specified objectives. The simultaneous evaluation of the input variables allows the proposed system (AGSPICE) to track the changes of these variables along the optimization process and its understanding in a clearer way. Our experimental results with the AGSPICE applied to an Operational Transconductance Amplifier (OTA) CMOS design are compared to the results obtained manually and present compatible solutions to other works available in the related literature.
\end{abstract}

Artigo submetido em 16/05/2011 (Id.: 1336)

Revisado em 19/08/2011, 22/11/2011, 23/02/2012

Aceito sob recomendação do Editor Associado Prof. Jés de Jesus Fiais Cerqueira
KEYWORDS: Evolutionary system, integrated circuit project, Genetic Algorithms, CMOS Operational Transconductance Amplifier.

\section{RESUMO}

O projeto de circuitos integrados analógicos é uma tarefa complexa devido ao grande número de variáveis de entrada a serem determinadas simultaneamente com o intuito de atender as inúmeras especificações de um projeto de circuito integrado analógico. Este trabalho descreve e implementa um sistema evolucionário baseado em Algoritmos Genéticos (AG) que foi integrado computacionalmente ao simulador de circuitos SPICE e tem a capacidade de buscar soluções que melhor atendam aos objetivos especificados pelo projetista. A avaliação simultânea das variáveis de entrada permite ao sistema proposto (AGSPICE) mapear o comportamento dessas variáveis em função das especificações do projeto ao longo do processo de otimização e o seu entendimento de forma mais clara. Os resultados dos experimentos realizados com o sistema AGSPICE para projeto de um Amplificador Operacional de Transcondutância (OTA) CMOS são comparados com os resultados obtidos manualmente e apresentam soluções compatíveis com aquelas descritas na literatura. 
PALAVRAS-CHAVE: Sistema evolucionário, projeto de circuito integrado, Algoritmos Genéticos, Amplificador Operacional de Transcondutância CMOS.

\section{INTRODUÇÃO}

O projeto de circuitos integrados (CIs) analógicos é uma tarefa complexa devido ao grande número de parâmetros de otimização envolvidos, tais como as dimensões dos transistores, dados pela largura (W) e comprimento (L) de canal, a corrente de polarização do circuito $\left(\mathrm{I}_{P O L}\right)$, a tensão de entrada em modo comum de polarização $\left(V_{I N P O L}\right)$ e também os diferentes objetivos de projeto, tais como o ganho de tensão em malha aberta $\left(A_{V 0}\right)$, a frequência de ganho de tensão unitário $\left(f_{T}\right)$, a margem de fase $(\mathrm{PM})$, as condições de polarização por tensão e corrente contínuas (DC), a potência total dissipada pelo circuito $\left(\mathrm{P}_{T O T}\right)$, a área de todos os transistores (AREA), os regimes de operação e inversão dos transistores, o Slew Rate (SR), a Razão de Rejeição em Modo Comum (CMRR), entre outros. Existem, de fato, inúmeras soluções possíveis baseadas, por exemplo, nas combinações das dimensões dos transistores e condições de regime de inversão que podem ser identificadas para alcançar um objetivo de projeto específico (Zebulum et. al., 2002). Na prática, a solução de um objetivo de projeto específico depende essencialmente da experiência do projetista (Zebulum et. al., 2002).

Este trabalho descreve e implementa um protótipo computacional baseado na técnica de Inteligência Artificial denominada Algoritmos Genéticos (AG) (Coello et. al., 2007; Goldberg, 1989; Zebulum et. al., 2002) que, programado para se comunicar automaticamente com o simulador de circuitos integrados Spice Opus (Spice Opus, 2009), constitui o sistema evolucionário designado aqui pela sigla AGSPICE. Este sistema permite realizar a otimização dos múltiplos parâmetros e especificações de projeto do amplificador operacional de transcondutância (OTA) de único estágio e única saída, construído com tecnologia CMOS, o qual é um bloco básico analógico importante na implementação de circuitos integrados tanto analógicos como digitais. O processo de busca do AGSPICE, neste caso, se propõe a avaliar sete diferentes objetivos de projeto do OTA ao mesmo tempo: $A_{V 0}, f_{T}$, PM, tensão de saída DC igual à metade da tensão de alimentação $\left(V_{D D}\right)$, ou seja, $V_{O U T}$ sendo igual a $V_{D D} / 2$ para permitir a máxima excursão do sinal de saída, $\mathrm{P}_{T O T}$, AREA e todos os transistores do circuito operando na região de saturação.

Há, na literatura afim, outros trabalhos que aplicam AG e outras técnicas de Inteligência Computacional para otimização de circuitos integrados analógicos, tais como (Santini, 2001; Barros et. al., 2005; Wójcikowski et al., 1996; Ando e Iba, 2000; McConaghy et. al., 2009). Por exemplo, o trabalho descrito em (Ando e Iba, 2000) aplica AG no projeto de filtros complexos, tais como filtros assimétricos, utilizando análise da resposta em frequência para avaliar o circuito. Em (Wójcikowski et al., 1996), um trabalho similar a este é apresentado, onde os autores aplicam AG no projeto de um amplificador operacional de transcondutância, mas com função de avaliação e circuito diferentes. Porém, acredita-se que o presente estudo seja inovador pois utiliza o AG não somente para determinar os melhores parâmetros para objetivos específicos de projeto do OTA, mas também para mapear e compreender o comportamento do processo de busca e otimização de todos os parâmetros de entrada que atendam esses objetivos simultaneamente. Em outras palavras, o sistema AGSPICE proposto mapeia as mudanças das dimensões W e L de todos os transistores do OTA, assim como a corrente de polarização do circuito e a tensão de entrada em modo comum. Este mapeamento permite investigar como estas mudanças afetam o processo de busca dos objetivos de projeto do OTA, quando operando em condições de micropotência, alto ganho de tensão e alta frequência, gerando ao final um conjunto de recomendações de projeto que podem auxiliar o projetista em especificações similares ou futuras.

Na próxima seção, seção 2 , descreve-se o Amplificador Operacional de Transcondutância (OTA). Na seção 3, apresentase um detalhamento da metodologia empregada e o procedimento utilizado no projeto manual de otimização do OTA. Na seção 4 , o sistema AGSPICE proposto e o procedimento de busca utilizado são descritos. Em seguida, nas seções 5 e 6, são apresentados e discutidos os resultados obtidos nos experimentos realizados através do AGSPICE, assim como os resultados obtidos de forma manual, sendo realizada, posteriormente, uma comparação entre os dois métodos. Na seção 7, discute-se algumas possíveis regras de projeto inferidas por este estudo. Por fim, na seção 8, apresenta-se uma conclusão dos resultados e discute-se as possibilidades de desenvolvimento subsequentes dessa pesquisa.

\section{CIRCUITO DO OTA CMOS E EQUA- ÇÕES BÁSICAS}

A Figura 1 mostra o circuito elétrico do OTA CMOS utilizado neste trabalho. Os transistores do circuito são do tipo convencional (bulk) e utilizam a tecnologia CMOS de 0,35 $\mu \mathrm{m}$ da AMIS (ON-Semiconductor), disponível no MOSIS Educational Program (MEP) (Mosis, 2009). O terminal de corpo de todos os transistores estão conectados aos seus respectivos terminais de fonte. Por simplicidade, os terminais de corpo não estão representados na Figura 1. Nesta figura, M1, M2, M7, M8, M9 e M10 são nMOSFETs, M3, M4, M5 e M6 são pMOSFETs, $\mathrm{C}_{L}$ é a carga capacitiva, $V_{D D}$ é a tensão de alimentação, GND é o terminal de terra (potencial de referência de $0 \mathrm{~V}), V_{I+}$ e $V_{I-}$ são as entradas diferenciais, onde $V_{I+}$ representa o terminal da entrada não inversora e $V_{I-} \mathrm{o}$ 
terminal da entrada inversora (Eggermont et al., 1996; Gimenez et al., 2003, 2005, 2006; Zebulum et. al., 2002). Os pares M3-M5, M4-M6, M7-M8 e M9-M10 estão configurados como espelhos de corrente. O espelho de corrente nMOSFET formado pelo par M9-M10 é responsável pela corrente de polarização do par diferencial. Neste projeto, o circuito será considerado simétrico, ou seja, os pares M1-M2, M3M4, M5-M6 e M7-M8 serão considerados casados (mesmas dimensões e características elétricas). Os transistores M9 e M10 serão considerados casados somente no projeto realizado manualmente, enquanto que, no caso do AGSPICE, não serão obrigatoriamente casados, ou seja, poderão apresentar dimensões W e L diferentes. Adicionalmente, $\mathrm{I}_{P O L}$ é a corrente de polarização; $\mathrm{I}_{O}$ é a corrente de saída do espelho de corrente composto dos transistores $\mathrm{M} 9$ e M10; $\mathrm{I}_{D S 1}$ e $\mathrm{I}_{D S 2}$ são as correntes entre dreno e fonte do par diferencial; $\mathrm{I}_{D S 3}$ e $\mathrm{I}_{D S 4}$ são as correntes entre dreno e fonte das cargas ativas do par diferencial; $\mathrm{I}_{D S 5}, \mathrm{I}_{D S 6}, \mathrm{I}_{D S 7}$ e $\mathrm{I}_{D S 8}$ são as correntes entre dreno e fonte dos transistores do estágio de saída M5, M6, M7 e M8, respectivamente.

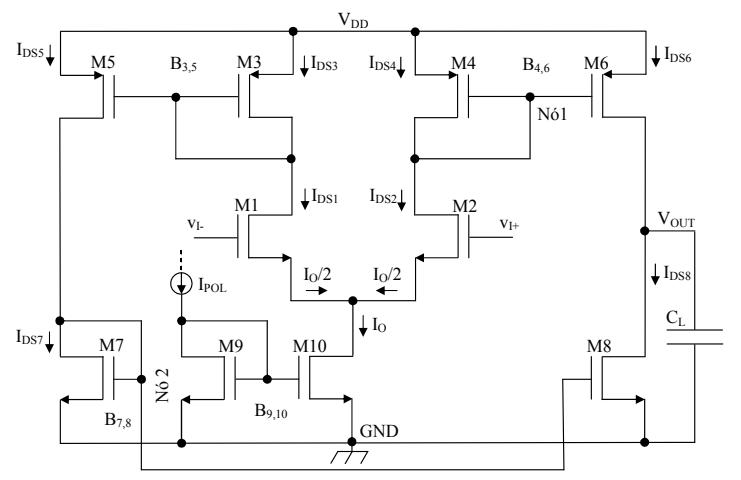

Figura 1: Circuito do OTA CMOS de um único estágio e uma única saída.

O fator de ganho do espelho de corrente pMOSFET formado por M4 e M6 $\left(B_{4,6}\right)$ é dado pela seguinte equação (Eggermont et al., 1996; Gimenez et al., 2003, 2005, 2006):

$$
B_{4,6}=\frac{I_{D S 6}}{I_{D S 4}}=\frac{(W / L)_{6}}{(W / L)_{4}}
$$

onde $(W / L)_{4}$ e $(W / L)_{6}$ correspondem às razões de aspecto, respectivamente dos transistores M4 e M6. Dada a simetria do circuito, será considerado o ganho do outro espelho de corrente pMOSFET $\left(B_{3,5}\right)$, formado por M3 e M5, igual a $B_{4,6}$. Também devido à simetria do circuito, o fator de ganho do espelho de corrente nMOSFET formado por M7 e M8, $B_{7,8}$, correspondente ao par M7-M8, será considerado igual a 1 .
O ganho do espelho de corrente formado pelo par M9-M10, $B_{9,10}$, analogamente a $B_{4,6}$, é dado pela seguinte equação (Eggermont et al., 1996; Gimenez et al., 2003, 2005, 2006):

$$
B_{9,10}=\frac{I_{0}}{I_{P O L}}=\frac{(W / L)_{10}}{(W / L)_{9}}
$$

onde $(W / L)_{9}$ e $(W / L)_{10}$ correspondem às razões de aspecto, respectivamente dos transistores M9 e M10. Como no projeto manual o par de transistores M9-M10 são considerados casados, $B_{9,10}$ será considerado igual a 1 e a corrente espelhada, $I_{O}$, será similar à corrente de referência $I_{P O L}$, porém, no caso do AGSPICE, $B_{9,10}$ poderá ser menor ou maior que 1, pois M9 e M10 não são necessariamente casados, resultando uma corrente espelhada, $I_{O}$, menor ou maior que $I_{P O L}$, respectivamente, dependendo da razão entre os fatores geométricos desses transistores.

Aplicando um pequeno sinal diferencial de tensão nas entradas diferenciais, as correntes de dreno dos transistores M1 e M2 são espelhadas para o nó de saída $\left(V_{O U T}\right)$ produzindo um sinal de tensão de saída amplificado. O ganho de tensão em malha aberta do OTA CMOS pode ser calculado como (Eggermont et al., 1996; Gimenez et al., 2003, 2005, 2006):

$$
A_{v o}=B_{4,6} \cdot\left(\frac{g_{m}}{I_{D S}}\right)_{1,2}\left(\frac{V_{A 6} \cdot V_{A 8}}{V_{A 6}+V_{A 8}}\right)
$$

onde $\left(g_{m} / I_{D S}\right)_{1,2}$ é o valor da razão da transcondutância pela corrente entre dreno e fonte do par diferencial M1-M2; $V_{A 6}$ e $V_{A 8}$ são as tensões Early dos transistores M6 e M8, respectivamente.

Desprezando-se os polos e zeros parasitas, os quais ocorrem devido às capacitâncias intrínsecas dos transistores do circuito, ter-se-á apenas o polo principal do sistema, o qual é, devido à capacitância de carga, $C_{L}$. Assim, o sistema poderá ser considerado de primeira ordem e a frequência de ganho de tensão unitário é então dada pelo produto do ganho de tensão $\left(A_{V 0}\right)$ pela frequência de corte $\left(f_{3 d B}\right)$, também conhecido por GBW (gain bandwidth product), dada pela equação 4. Este é normalmente o caso, pois estes polos e zeros, que ocorrem devido às capacitâncias intrínsecas localizadas nos nós 1 e 2, devem estar posicionados suficientemente além de $f_{T}$ para garantir margem de fase positiva e operação estável do OTA (Eggermont et al., 1996; Gimenez et al., 2003, 2005, 2006), ou seja,

$$
f_{T}=A_{V 0} \cdot f_{3 d B}=B_{4,6} \cdot\left(\frac{g_{m}}{I_{D S}}\right)_{1,2}\left(\frac{I_{D S 1,2}}{2 \cdot \pi \cdot C_{L}}\right) .
$$


As equações (1)-(4) são de primeira ordem e formam a base do projeto que é realizado manualmente, com a finalidade de comparação com os resultados obtidos através do AGSPICE.

Diferentemente do projeto manual, o AGSPICE obtém os resultados do conjunto de possíveis soluções encontradas através do simulador de circuitos integrados Spice Opus (Spice Opus, 2009), para posteriormente serem avaliados através das equações de avaliação (detalhadas na seção 4) com o objetivo de quantificar o grau de adequação dos resultados obtidos pelo simulador.

\section{METODOLOGIA DO PROJETO MA- NUAL}

Uma vez que o procedimento de projeto manual está baseado na metodologia do projeto de circuitos integrados analógicos dada por $\mathrm{g}_{m} / \mathrm{I}_{D S} \times \mathrm{I}_{D S} /(\mathrm{W} / \mathrm{L})$ (Silveira et al., 1996), primeiramente deve-se caracterizar a tecnologia a ser utilizada para obtenção dos parâmetros pertinentes e das curvas $\mathrm{g}_{m} / \mathrm{I}_{D S} \mathrm{X}$ $\mathrm{I}_{D S} /(\mathrm{W} / \mathrm{L})$ e $V_{A} \times \mathrm{L}$ (Cortes, 2003).

A tecnologia CMOS de $0,35 \mu \mathrm{m}$ da AMIS (ONSemiconductor) (Mosis, 2009) é utilizada neste trabalho. Assim, a curva $\mathrm{g}_{m} / \mathrm{I}_{D S} \times \mathrm{I}_{D S} /(\mathrm{W} / \mathrm{L})$ foi obtida através de simulações no simulador de circuitos Spice Opus (Spice Opus, 2009), utilizando o modelo BSIM3 versão 3.1 disponibilizado pelo MOSIS (Mosis, 2009) do referido fabricante. Estes parâmetros, fornecidos pelo MOSIS, foram adequados para serem utilizados no simulador Spice Opus (Spice Opus, 2009) através do manual deste software (Tuma e Búrmen, 2009). Por exemplo, o parâmetro LEVEL (nível) varia de acordo com o fabricante do simulador SPICE, que no caso deste simulador deve ser definido como nível 53. Para a obtenção dessa curva foi seguido um procedimento similar ao descrito em (Cortes, 2003).

O parâmetro Tensão Early $\left(V_{A}\right)$ é essencial para o projeto analógico CMOS, pois os estágios de ganho de um amplificador CMOS dependem deste parâmetro. Este parâmetro depende do efeito da modulação do comprimento efetivo de canal. Este efeito é caracterizado pela diminuição do comprimento de canal, com o aumento da tensão entre dreno e fonte $\left(V_{D S}\right)$ na região de saturação, ou seja, o efeito em que a corrente entre dreno e fonte $\left(\mathrm{I}_{D S}\right)$ aumenta lentamente em função do aumento de $V_{D S}$. Desta forma, pode-se obter o valor de $V_{A}$ a partir da curva $\mathrm{I}_{D S} \mathrm{x} V_{D S}$ do transistor MOS, através do prolongamento da curva $\mathrm{I}_{D S} \times V_{D S}$ na região de saturação até encontrar o eixo de $V_{D S}$. Portanto, para a obtenção dos valores de $V_{A}$ para a tecnologia CMOS de $0,35 \mu \mathrm{m}$ da AMIS (ON-Semiconductor) (Mosis, 2009) foi seguido um procedimento similar ao descrito em (Cortes, 2003).
Como é aplicada uma tensão de entrada em modo comum $\left(V_{C M}\right)$ para polarização do circuito, a tensão DC aplicada às entradas diferenciais $V_{I+}$ e $V_{I-}$ são exatamente iguais e as correntes $\mathrm{I}_{D S 1}(\mathrm{M} 1)$ e $\mathrm{I}_{D S 2}(\mathrm{M} 2)$ terão o mesmo valor e cada qual a metade da intensidade de $\mathrm{I}_{O}$, em primeira aproximação. O valor de $\mathrm{I}_{O}$ é equivalente a $B_{9,10} \cdot \mathrm{I}_{P O L}$, onde $B_{9,10}$ é o fator de ganho do espelho de corrente formado pelos transistores M9 e M10. Os espelhos de corrente formados pelos pares M4-M6 e M3-M5 espelham a corrente do par diferencial para os transistores de saída (M5-M6 e M7-M8), com um fator de ganho $B_{4,6}$ (ou $B_{3,5}$ ), ou seja, $\mathrm{I}_{D S 6}=B_{4,6} \cdot \mathrm{I}_{D S 2} \mathrm{e}$ $\mathrm{I}_{D S 5}=B_{3,5} \cdot \mathrm{I}_{D S 1}$. Considerando a simetria do circuito, $\mathrm{I}_{D S 1}$ $=\mathrm{I}_{D S 2}, \mathrm{I}_{D S 5}=\mathrm{I}_{D S 6}$ e $B_{3,5}=B_{4,6}$, então a corrente de cada transistor do par diferencial será representada por $\mathrm{I}_{D S 1,2}$ e a corrente do par de transistores do estágio de saída M5-M6, por $\mathrm{I}_{D S 5,6}$. Uma vez que M7 está em série com M5 e M8 está em série com M6, $\mathrm{I}_{D S 7,8}=\mathrm{I}_{D S 5,6}$. Além disso, o par M7-M8, em espelho de corrente, é assumido casado, ou seja, $B_{7,8}$ é considerado igual a 1 para preservar a simetria do circuito.

Com as equações básicas do circuito e os parâmetros da tecnologia a ser utilizada devidamente caracterizados, o projetista deve fornecer os objetivos e dados de projeto, tais como $A_{V 0} ; f_{T} ; \mathrm{PM} ; B_{4,6} ; B_{9,10}$; potência total dissipada $\left(\mathrm{P}_{T O T}\right)$ e a tensão de alimentação $\left(V_{D D}\right)$. Então, a metodologia do projeto manual é realizada conforme o fluxograma da Figura 2 , podendo ser utilizada para o dimensionamento de todos os transistores do circuito do OTA (M1 a M10).

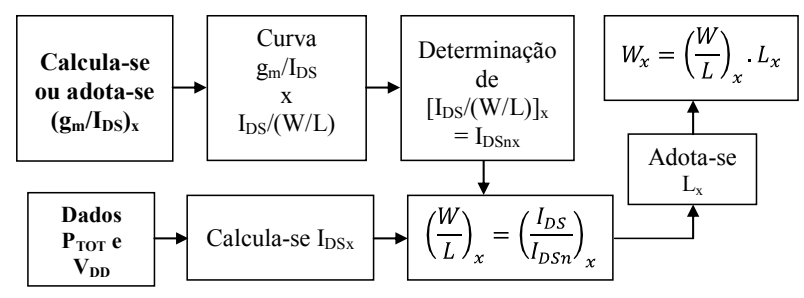

Figura 2: Fluxograma do projeto manual.

Inicialmente calcula-se, quando possível, ou adota-se o valor do parâmetro $\left(\mathrm{g}_{m} / \mathrm{I}_{D S}\right)_{x}$ de um determinado transistor transistor $\mathbf{M}_{x}$ do circuito do OTA, $\mathbf{x}(\in[1,10]$. Obtido o valor $\left(\mathrm{g}_{m} / \mathrm{I}_{D S}\right)_{x}$ de um determinado transistor $\mathrm{M}_{x}$ do OTA, a correspondente corrente entre dreno e fonte normalizada em função de $\mathrm{W} / \mathrm{L}\left(\mathrm{I}_{D S n x}\right)$, equivalente a $\left[\mathrm{I}_{D S} /(\mathrm{W} / \mathrm{L})\right]_{x}$, pode ser obtida através da curva $\mathrm{g}_{m} / \mathrm{I}_{D S} \times \mathrm{I}_{D S} /(\mathrm{W} / \mathrm{L})$, conforme o fluxograma da Figura 2 . Com a corrente entre dreno e fonte de um determinado transistor $\left(\mathrm{I}_{D S x}\right)$, calculada a partir dos dados e objetivos de projeto e a respectiva corrente normalizada $\left(\mathrm{I}_{D S n x}\right)$, a razão de aspecto $\left[(W / L)_{x}\right]$ pode ser calculada conforme o fluxograma. A largura de canal de um determinado transistor $\left(\mathrm{W}_{x}\right)$ pode ser obtida multiplicando 
a razão de aspecto pelo comprimento de canal adotado pelo projetista $\left(\mathrm{L}_{x}\right)$, conforme indicado no fluxograma.

A etapa de dimensionamento dos transistores (primeira tentativa) baseada na metodologia $\mathrm{g}_{m} / \mathrm{I}_{D S} \times \mathrm{I}_{D S} /(\mathrm{W} / \mathrm{L})$ e nas equações básicas do circuito de primeira ordem é então realizada. Os resultados obtidos devem ser avaliados pelo SPICE procedendo-se interativa e repetitivamente com o simulador até que as especificações de projeto possam ser alcançadas. Esse processo é lento, pois o projetista geralmente ajusta um único parâmetro do circuito em cada nova tentativa de simulação no SPICE, para então reavaliar os resultados obtidos. Caso os resultados não sejam satisfatórios, devem ser alterados valores de $\mathrm{g}_{m} / \mathrm{I}_{D S} ; B_{4,6} ; B_{9,10} ; \mathrm{W}$ e $\mathrm{L}$ a fim de realizar uma nova interação com o simulador SPICE na tentativa de obter soluções satisfatórias para todos os objetivos de projeto. Considerando que existem diversas especificações de projeto concorrentes, o ajuste adequado de uma determinada especificação de projeto acarreta em prejuízo de outras especificações, de forma que o ajuste do conjunto das variáveis de entrada do circuito para obter um bom compromisso entre diversas especificações de projeto também demanda muita experiência do projetista.

\section{METODOLOGIA EVOLUCIONÁRIA}

O objetivo deste trabalho é estudar e investigar a aplicação de um sistema evolucionário baseado em Algoritmos Genéticos (AG), integrado computacionalmente ao simulador de circuitos SPICE e denominado aqui de AGSPICE, para o processo de busca de soluções plausíveis para diversas especificações de projeto de um circuito integrado analógico denominado Amplificador Operacional de Transcondutância (OTA) de único estágio e única saída. Durante este processo, as variáveis livres de projeto, tais como as dimensões de largura (W) e comprimento de canal (L) dos MOSFETs, a corrente de polarização $\left(\mathrm{I}_{P O L}\right)$ e a tensão de entrada em modo comum para polarização do circuito $\left(V_{I N P O L}\right)$ são mapeadas e as especificações de projeto, tais como o ganho de tensão em malha aberta $\left(A_{V 0}\right)$, a frequência de ganho de tensão unitário $\left(f_{T}\right)$, a margem de fase (PM), a potência total dissipada $\left(\mathrm{P}_{T O T}\right)$ e a área total de todos os transistores do circuito (AREA) são monitoradas.

São dados de entrada para o AGSPICE: dados de projeto como o valor da tensão de alimentação $\left(V_{D D}\right)$, a capacitância de carga $\left(\mathrm{C}_{L}\right)$, as especificações de projeto e as restrições de projeto, tais como as larguras de canal mínimas e máximas dos transistores $\left(\mathrm{W}_{x \min }\right.$ e $\mathrm{W}_{x \max }$ ), os comprimentos de canal mínimos e máximos dos transistores $\left(\mathrm{L}_{x \min }\right.$ e $\mathrm{L}_{x \max }$ ), as correntes de polarização mínima e máxima $\left(\mathrm{I}_{P O L \min } \mathrm{e}\right.$ $\left.\mathrm{I}_{P O L \max }\right)$ e as tensões de entrada em modo comum mínima e máxima ( $V_{I N P O L \min }$ e $\left.V_{I N P O L \max }\right)$. São considerados também dados da tecnologia dos transistores do OTA (parâ- metros do simulador de circuitos SPICE). Estes dados são pré-estabelecidos pelo projetista, conforme ilustrado na Figura 3.

A Figura 4 ilustra o fluxograma de execução do AGSPICE, onde são detalhados os processos que o compõem. O simulador SPICE atua gerando os resultados das simulações das soluções potenciais geradas pelo algoritmo genético para posteriormente serem avaliados pelo AGSPICE, conforme mostra a Figura 3. O fluxograma da Figura 4 mostra os blocos de atuação do simulador SPICE, destacados com linha tracejada vermelha.

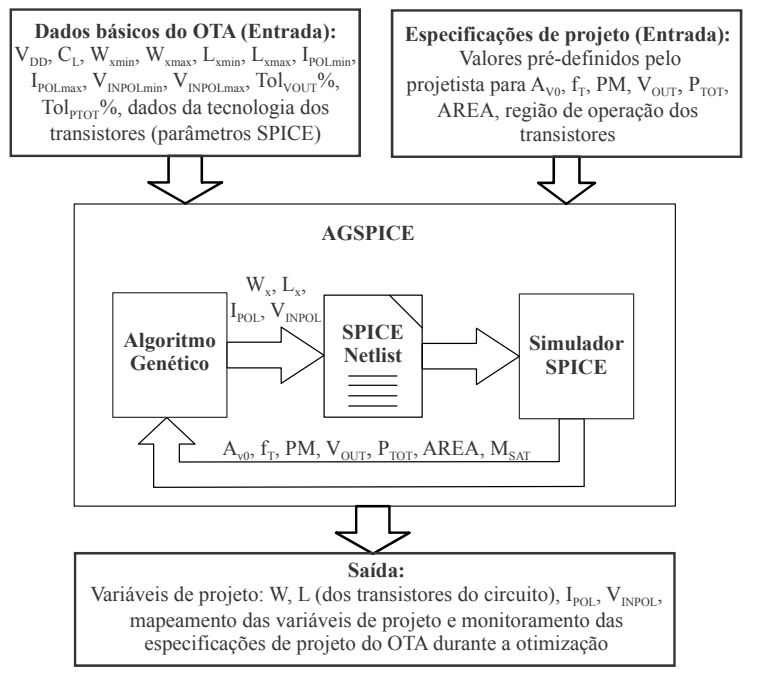

Figura 3: Diagrama simplificado dos dados de entrada e saída do AGSPICE.

O AGSPICE empregado nos experimentos realiza a busca em duas etapas, a etapa DC e a etapa AC. A etapa DC permite aumentar a velocidade de busca do AGSPICE. Este procedimento é baseado na técnica que é utilizada para fazer a análise da resposta em frequência de um amplificador por um projetista de $\mathrm{CI}$ analógico, ou seja, primeiro realiza-se a etapa DC para depois ser realizada a etapa AC (análise de pequenos sinais). A etapa AC no AGSPICE é definida como o processo de busca de soluções no qual são avaliados todos os objetivos de projeto. A evolução da etapa DC ocorre de maneira similar à etapa $\mathrm{AC}$. A única diferença é que na etapa DC somente são avaliados os objetivos relacionados ao ponto de operação do OTA, ou seja, $V_{O U T}=V_{D D} / 2, \mathrm{P}_{T O T}$, AREA e todos os transistores do circuito operando na região de saturação. Dessa forma, a etapa DC é representada de forma simplificada no fluxograma da Figura 4.

O processamento do AGSPICE ocorre da seguinte forma: inicialmente gera-se soluções DC, representadas por $\mathrm{W}_{x}, \mathrm{~L}_{x}$, $\mathrm{I}_{P O L}$ e $V_{I N P O L}, \mathrm{x}(\in[1,10]$, que são as variáveis de entrada (variáveis livres) do circuito, através dos operadores ge- 


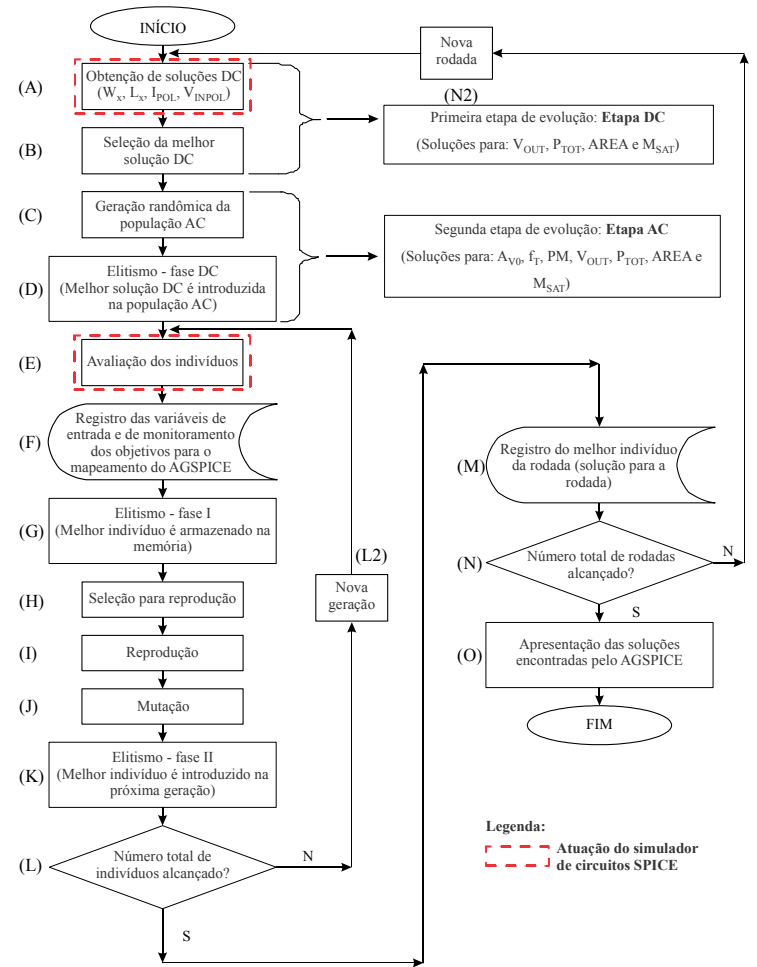

Figura 4: Fluxograma do AGSPICE.

néticos de seleção, reprodução e mutação (de forma análoga à etapa $\mathrm{AC}$ ), conforme indicado no processo (A) do fluxograma (Figura 4), sendo que o número de soluções DC apresentadas ao final deste processo é igual ao número de rodadas DC, configurado no programa AGSPICE. Então, o sistema evolucionário seleciona a melhor solução DC gerada na etapa anterior, conforme indicado no processo (B) do fluxograma. Inicia-se, então, a etapa AC com uma população gerada com valores randômicos, conforme indicado no processo (C) do fluxograma.

O passo seguinte é a etapa do elitismo DC. Nesta etapa, a melhor solução DC do OTA, selecionada no processo (B), substitui um indivíduo da população AC inicial, o qual é sorteado aleatoriamente, conforme indicado no processo (D) do fluxograma. A etapa do elitismo DC é ilustrada na Figura 5. A representação das soluções (cromossomas) no AGSPICE é detalhada na Figura 6.

Com a população AC inicial gerada, os valores de $\mathrm{W}_{x}, \mathrm{~L}_{x}$, $\mathrm{I}_{P O L}$ e $V_{I N P O L}$ de cada indivíduo são incluídos em arquivos netlist do Spice Opus (Spice Opus, 2009). Netlist é um arquivo texto que contém a descrição do circuito do OTA, juntamente com os parâmetros dos nMOSFETs e pMOSFETs do modelo BSIM3 versão 3.1 disponibilizado pelo MOSIS (Mosis, 2009), para a tecnologia CMOS de 0,35 $\mu \mathrm{m}$ da
AMIS (ON-Semiconductor). Dessa forma, o AGSPICE cria um arquivo netlist com as variáveis de entrada do circuito para cada indivíduo dessa população, juntamente com $V_{D D}$ e $\mathrm{C}_{L}$, configurados pelo projetista no programa AGSPICE, os quais são mantidos fixos durante o processo de busca. Então são realizadas simulações no simulador Spice Opus (Spice Opus, 2009), para cada indivíduo da população. Com os resultados gerados através do simulador, cada indivíduo é avaliado por meio de equações de avaliação (definidas mais adiante), conforme indicado no processo (E) do fluxograma.

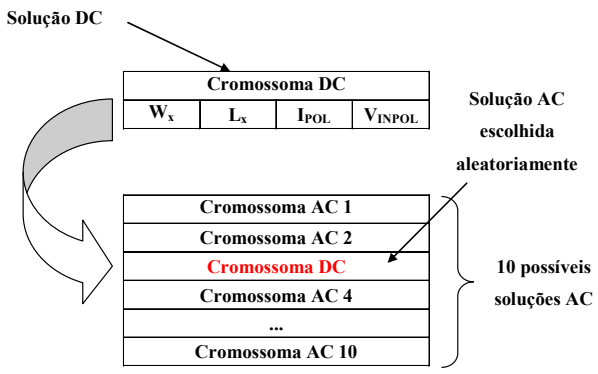

Figura 5: Elitismo DC.

As variáveis de entrada e de monitoramento das especificações de projeto, tais como $A_{V 0}, f_{T}, \mathrm{PM}, V_{O U T}, \mathrm{P}_{T O T} \mathrm{e}$ AREA correspondente ao indivíduo com o maior valor de avaliação, obtido na etapa anterior, são registradas em arquivo com a finalidade de realizar o mapeamento do processo de otimização do AGSPICE, conforme indicado no processo (F) do fluxograma.

Na próxima etapa, ocorre a primeira fase do elitismo, indicado no processo $(\mathrm{G})$ do fluxograma, em que o melhor indivíduo avaliado é armazenado na memória para ser utilizado futuramente.

Em seguida, o processo de seleção é realizado, conforme indicado no processo $(\mathrm{H})$ do fluxograma. Este processo seleciona pares de indivíduos, que são usados no processo de reprodução (crossover). Os indivíduos são selecionados através do método da roleta (Coello et. al., 2007; Goldberg, 1989). Neste método, as soluções com melhores avaliações possuem maiores chances de serem selecionadas para reprodução que as outras. Embora os indivíduos com melhores valores de avaliação tenham maior probabilidade de serem escolhidos, os indivíduos com menores valores de avaliação também podem ser escolhidos, garantindo a diversidade de soluções apresentadas pelo AGSPICE.

$\mathrm{Na}$ etapa da reprodução do sistema evolucionário, indicada no processo (I) do fluxograma, grupos de bits dos genes $\mathrm{W}_{x}$, $\mathrm{L}_{x}, \mathrm{I}_{P O L}$ e $V_{I N P O L}$ dos indivíduos selecionados são trocados utilizando o crossover de um ponto (Coello et. al., 2007; Zebulum et. al., 2002; Goldberg, 1989). A taxa do processo 
de reprodução (taxa de crossover) é um parâmetro de entrada do algoritmo e deve ser selecionado pelo projetista no programa AGSPICE, sendo utilizada uma faixa de $65 \%$ a $70 \%$ para este parâmetro nos projetos realizados. Então, ocorre a mutação de alguns indivíduos, conforme indicado no processo (J) do fluxograma. Como a representação do cromossoma é realizada em números binários, a etapa da mutação essencialmente inverte alguns bits que compõem os genes $\mathrm{W}_{x}, \mathrm{~L}_{x}, \mathrm{I}_{P O L}$ e $V_{I N P O L}$. Analogamente à taxa de crossover, a taxa de mutação também é um parâmetro de entrada e deve ser configurado pelo projetista no programa AGSPICE, sendo utilizada uma taxa de $3 \%$ em todos os projetos realizados neste trabalho.

Após as etapas de seleção, reprodução e mutação, uma nova geração é criada. A fim de garantir que esta nova população gerada tenha avaliação no mínimo igual à geração anterior aplica-se a segunda etapa do elitismo, indicada no processo (K) do fluxograma, em que o sistema evolucionário escolhe aleatoriamente um indivíduo desta nova geração, substituindo pelo indivíduo com o melhor valor de avaliação da geração anterior.

O AGSPICE continua processando novas gerações até alcançar o número total de indivíduos definido pelo projetista, conforme indicado nos processos (L) e (L2) do fluxograma. O número total de indivíduos é um parâmetro de entrada do AGSPICE e representa o total de indivíduos que deve ser gerado pelo algoritmo, considerando que cada geração cria $\mathrm{N}$ novos individuos, ou seja, uma nova população. No final, uma rodada do algoritmo é finalizada e a melhor solução encontrada representa a melhor solução do AGSPICE para esta rodada particular. A solução e os resultados de desempenho obtidos para a rodada são, então, registrados em arquivo, conforme indicado no processo (M) do fluxograma. Uma nova rodada significa começar o processo de evolução do AGSPICE novamente, ou seja, inicia-se uma nova etapa DC e, em seguida, uma nova etapa AC é iniciada com uma população gerada randomicamente, conforme indicado nos processos $(\mathrm{N})$ e (N2) do fluxograma. O projetista deve escolher o número de rodadas e, quanto maior for o número de rodadas, maior será o número de possíveis soluções apresentadas no final do processo de busca do AGSPICE, indicado no processo $(\mathrm{O})$ do fluxograma.

No AGSPICE todas as possíveis soluções do projeto do OTA estão codificadas em estruturas chamadas cromossomas. Dentro de cada cromossoma estão localizados os genes, sendo que cada gene codifica uma variável de projeto. Dessa forma, os genes do cromossoma codificam as dimensões de todos os transistores, a corrente e a tensão de polarização do circuito do OTA. A Figura 6 mostra a representação do cromossoma das soluções potenciais do AGSPICE. Todos os genes alelos $\mathrm{W}_{x}, \mathrm{~L}_{x}, \mathrm{I}_{P O L}$ e $V_{I N P O L}, \mathrm{x} \in[1,10]$, são números binários. Cada um destes genes possui um determinado número de bits especificado em função da faixa de números reais que representam e também da precisão desejada para a grandeza correspondente. Uma vez que $\mathrm{M} 1=\mathrm{M} 2$, M3=M4, M5=M6 e M7=M8, os alelos de número ímpar das dimensões $\mathrm{W}$ e $\mathrm{L}$ destes transistores não foram incluídos no cromossoma, pois são iguais aos respectivos alelos de número par devido à simetria do circuito. É importante notar que os transistores M9 e M10, que formam o espelho de corrente que polariza o par diferencial, não são casados. Dessa forma, as dimensões $\mathrm{W}$ e $\mathrm{L}$ destes transistores podem variar livremente durante o processo de busca para atender os múltiplos objetivos do OTA.

Quando o valor do ganho do espelho de corrente pMOSFET $\left(B_{4,6}\right)$, assim como o ganho do espelho nMOSFET da fonte de corrente $\left(B_{9,10}\right)$ são unitários, ou seja, $B_{4,6}=B_{9,10}=1$, dados $\mathrm{P}_{T O T}$ e $V_{D D}$, temos uma corrente de polarização fixa igual a $1 / 3$ do valor da corrente total drenada pelo circuito $\left(\mathrm{I}_{T O T}\right)$. Como os valores de $B_{4,6}$ e $B_{9,10}$ não são pré-fixados pode-se obter valores maiores ou menores que este valor de referência para $\mathrm{I}_{P O L}$. A faixa de valores assumida pelo gene $\mathrm{I}_{P O L}$ pode ser estimada com base na potência dissipada pelo circuito, com valores em torno de $\mathrm{I}_{T O T} / 3$, podendo ser adotado o valor de $\mathrm{I}_{P O L \min }$ menor e o valor de $\mathrm{I}_{P O L \max }$ maior que este valor de referência, a fim de possibilitar que os valores de $B_{4,6}$ e de $B_{9,10}$ sejam maiores ou menores do que 1 , no processo de busca dos múltiplos objetivos do OTA pelo AGSPICE.

O gene $V_{I N P O L}$ foi incluído no cromossoma do AGSPICE, podendo variar de uma faixa de $0,7 \mathrm{~V}$ (aproximadamente a tensão de limiar do transistor nMOSFET) até $V_{D D}$ (tensão de alimentação do circuito), a fim de garantir que todos os transistores do circuito do OTA operem na região de saturação, especialmente o transistor da fonte de corrente M10 (Allen e Holberg, 2002).

\begin{tabular}{|c|c|c|c|c|c|}
\hline \multicolumn{7}{|c|}{ Cromossoma } \\
\hline $\mathbf{W}_{2}$ & $\mathbf{W}_{4}$ & $\mathbf{W}_{6}$ & $\mathbf{W}_{8}$ & $\mathbf{W}_{9}$ & $\mathbf{W}_{10}$ \\
\hline $\mathbf{L}_{2}$ & $\mathbf{L}_{4}$ & $\mathbf{L}_{6}$ & $\mathbf{L}_{8}$ & $\mathbf{L}_{9}$ & $\mathbf{L}_{10}$ \\
\hline \multicolumn{7}{|c|}{$\mathbf{I}_{P O L}$} \\
\hline \multicolumn{7}{|c|}{$\mathbf{V}_{I N O L}$} \\
\hline
\end{tabular}

Figura 6: Representação do Cromossoma do AGSPICE.

$\mathrm{O}$ número de bits dos genes $\mathrm{W}_{x}, \mathrm{~L}_{x}, \mathrm{I}_{P O L}$ e $V_{I N P O L}$ são calculados conforme mostra a equação (5), onde $\mathrm{y}_{R \max } \mathrm{e}$ $\mathrm{y}_{\text {Rmin }}$ representam os valores máximo e mínimo, respectivamente, de uma grandeza representada no cromossoma, por exemplo $\mathrm{W}_{x \max } \mathrm{e} \mathrm{W}_{x \min }$, onde $\mathrm{W}_{x \max } \mathrm{e} \mathrm{W}_{x \min }$ representam o valor máximo e o valor mínimo, respectivamente, da largura de canal de um MOSFET $\mathbf{M}_{x}$ do circuito do OTA, $\mathrm{x}$ 
$\in[1,10]$, especificados no programa AGSPICE em $[\mu \mathrm{m}] \mathrm{e}$ P é a precisão desejada, por exemplo $0,01 \mu \mathrm{m}$ :

$$
n=\frac{\log \left[\frac{\left(y_{R_{\max }}-y_{R_{\min }}\right)}{P}+1\right]}{\log (2)} .
$$

Neste trabalho, é realizada uma busca por soluções que atendam a objetivos pré-estabelecidos pelo projetista. Por esta razão a função de avaliação do AGSPICE deve retornar um índice de afinidade entre o valor obtido pelo indivíduo e o valor objetivado pelo projetista. Dessa maneira, o valor de avaliação para a solução do problema no AGSPICE será esse índice de afinidade, priorizando soluções que se aproximem mais dos objetivos pré-estabelecidos pelo projetista.

Para solucionar esse problema é necessária uma função monotonicamente decrescente, de maneira a avaliar os indivíduos (soluções) do AGSPICE de forma gradual, tendo como valor máximo de avaliação soluções que atendam plenamente os objetivos pré-estabelecidos pelo projetista (Rego et al., 2009). Assim, uma função Gaussiana é empregada na avaliação de cada uma das seis seguintes especificações de projeto consideradas aqui: $A_{V 0}, f_{T}, \mathrm{PM}, V_{O U T}, \mathrm{P}_{T O T}$, AREA. Porém para a avaliação da região de operação dos transistores do circuito é utilizada uma função do tipo degrau.

A função Gaussiana retorna um valor de avaliação entre 0 e 100 , sendo que quanto mais próximo de 100 for o resultado da avaliação, maior é a proximidade entre o valor obtido pelo indivíduo e o valor objetivado pelo projetista. A equação geral de avaliação dos objetivos é definida da seguinte maneira (Rego et al., 2009):

$$
\operatorname{Eval}(\operatorname{Obj}(i))=100 \cdot \exp \left(-\frac{\text { DesvioRelativo }^{2}}{2 . \sigma^{2}}\right)
$$

onde:

$$
\text { Desvio Relativo }=\left(\frac{O b j(i)-O b j \_D e s}{O b j \_D e s}\right)
$$

Eval(Obj(i)) representa o valor de avaliação obtido por um indivíduo com relação a um determinado objetivo $\left(A_{V 0}, f_{T}\right.$, $\mathrm{PM}$, etc.); Obj(i) representa o valor de um objetivo obtido por um determinado indivíduo i do AGSPICE; Obj_Des representa o valor desejado de um determinado objetivo estabelecido pelo projetista e $\sigma^{2}$ é a variância da curva Gaussiana. A variância modifica o espalhamento desta curva e, no caso deste trabalho, essa variável pode ser configurada no programa AGSPICE a critério do projetista. Esse valor pode ser ajustado experimentalmente por uma análise de desempenho do AGSPICE, através da análise do tempo de convergência do sistema na busca de soluções satisfatórias e também da proximidade das soluções obtidas em relação ao objetivo.

$\mathrm{Na}$ equação de avaliação (6), observa-se que no numerador da exponencial decrescente é calculado o quadrado do desvio relativo entre o valor obtido para um determinado objetivo e o valor desejado para este objetivo, em vez de ser calculado o quadrado do desvio absoluto, em que os valores obtidos e desejados seriam subtraídos diretamente. O significado dessa operação é a normalização dos valores objetivo e obtido pelo indivíduo, independentemente de sua grandeza.

Para as especificações de $A_{V 0}, f_{T}, \mathrm{PM}, V_{O U T}, \mathrm{P}_{T O T}$ e AREA, onde AREA é o valor da somatória do produto $\mathrm{W}$ $\mathrm{x}$ L de todos os transistores do circuito, as funções de avaliação correspondentes são definidas pelas equações (6) e (7).

No programa AGSPICE, foram adotadas restrições de valores para as faixas de valores admissíveis para a tensão de saída DC $\left(V_{O U T}\right)$ e para a potência dissipada $\left(\mathrm{P}_{T O T}\right)$, com valores na faixa de $V_{D D} / 2 \pm 5 \%$ e $\mathrm{P}_{T O T} \pm 20 \%$, ou seja, foi admitida uma tolerância de $5 \%$ para $V_{O U T}$ e $20 \%$ para $\mathrm{P}_{T O T}$. Esses valores de tolerância são parâmetros de entrada ajustados no AGSPICE. Estas restrições são aplicadas nas funções de avaliação correspondentes a estes objetivos, no sentido de penalizar as soluções que apresentam valores fora dessas faixas de tolerância especificadas com valores iguais a zero.

Por último, se um determinado transistor do circuito do OTA, designado genericamente por $\mathbf{M}_{x}$, estiver operando na região de saturação:

$$
M_{x(S A T)}(i)=10, \mathrm{x} \in[1,10]
$$

caso contrário, o transistor estiver operando na região de triodo:

$$
M_{x(S A T)}(i)=0, \mathrm{x} \in[1,10]
$$

assim, avalia-se a região de operação de todos os transistores do circuito da seguinte forma:

$$
\operatorname{Eval}\left(M_{S A T}(i)\right)=\sum_{\mathrm{x}=1}^{10} M_{x(S A T)}(i)
$$

onde $\operatorname{Eval}\left(\mathrm{M}_{S A T}(\mathrm{i})\right)$ é o valor de avaliação obtido por um indivíduo, com relação à região de operação de todos os transistores do circuito (M1 a M10); $\mathbf{M}_{x(S A T)}(\mathrm{i})$ representa a re- 
gião de operação de um determinado transistor do circuito (x $\in[1,10])$, para um determinado indivíduo i do AGSPICE, relacionada pelas equações (8) e (9).

A função de avaliação global da solução, ou função de avaliação dos múltiplos objetivos de um indivíduo i [ $\left.\operatorname{Eval}_{A G}(\mathrm{i})\right]$, é a soma ponderada das funções de avaliação de todas as especificações de projeto consideradas, ou seja:

$$
\begin{aligned}
\operatorname{Eval}_{A G}(i) & =P_{A V 0} \cdot \operatorname{Eval}\left(A_{V 0}(i)\right)+ \\
& +\mathrm{P}_{\mathrm{fT}} \cdot \operatorname{Eval}\left(f_{T}(i)\right)+ \\
& +\mathrm{P}_{\mathrm{PM}} \cdot \operatorname{Eval}(P M(i))+ \\
& +P_{\text {VOUT }} \cdot \operatorname{Eval}\left(V_{\text {OUT }}(i)\right)+ \\
& +\mathrm{P}_{\mathrm{PTOT}} \cdot \operatorname{Eval}\left(P_{T O T}(i)\right)+ \\
& +P_{A R E A} \cdot \operatorname{Eval}(A R E A(i))+ \\
& +\mathrm{P}_{\mathrm{MSAT}} \cdot \operatorname{Eval}\left(M_{S A T}(i)\right),
\end{aligned}
$$

onde $\operatorname{Eval}_{A G}(\mathrm{i})$ é a avaliação dos múltiplos objetivos de um indivíduo i da população do AGSPICE e $\mathrm{P}_{A V 0}, \mathrm{P}_{f T}, \mathrm{P}_{P M}$, $\mathrm{P}_{V O U T}, \mathrm{P}_{P T O T}, \mathrm{P}_{A R E A}, \mathrm{P}_{M S A T}$ são, respectivamente, os pesos atribuídos pelo projetista para $A_{V 0}, f_{T}, \mathrm{PM}, V_{O U T}$, $\mathrm{P}_{T O T}$, AREA e $\mathrm{M}_{S A T}$, sendo que a soma de todos os pesos deve totalizar $100 \%$.

Portanto, o AGSPICE realizará a busca das melhores soluções através dos maiores valores da função de avaliação, dada pela equação (11), que tentam atender aos valores prédefinidos para cada uma das sete especificações do OTA estabelecidas neste trabalho.

\section{EXPERIMENTOS}

Para os testes experimentais, a metodologia descrita na seção 4 foi desenvolvida em linguagem C++ (Microsoft Visual Studio, 2008). A execução do código compilado foi realizado em uma máquina de arquitetura IBM-PC, equipada com processador AMD Athlon(tm) $643000+$ com 2,00 GHz de clock e 1,5 GB de memória RAM instalada. O sistema operacional utilizado foi o Windows 7 Ultimate (64 bits). A Figura 7 mostra a visualização de um processo de busca em tempo real na janela principal do AGSPICE.

Com o objetivo de mapear as dimensões $\mathrm{W}$ e $\mathrm{L}$, a corrente de polarização $\left(\mathrm{I}_{P O L}\right)$, a tensão de entrada em modo comum $\left(V_{I N P O L}\right)$ e ainda monitorar a evolução dos diferentes objetivos de projeto para o OTA durante o processamento do AGSPICE, quatro modos de operação são investigados, sendo denominados: Micropotência1, Micropotência2, HG e HF.

O OTA Micropotência1 opera em micropotência, com ganho de tensão mediano e com baixa frequência de ganho unitário em comparação aos demais OTAs. O OTA Micropotência2 opera em micropotência, com alto ganho de tensão e com

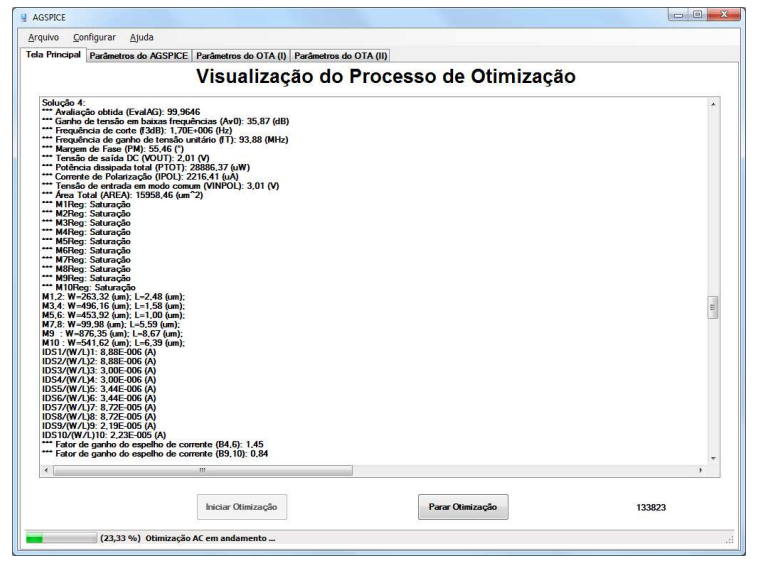

Figura 7: llustração da janela principal do AGSPICE.

baixa frequência de ganho unitário em comparação aos demais OTAs. O OTA HG opera em média potência, com alto ganho de tensão e com média frequência de ganho unitário em comparação aos demais OTAs analisados. E, por último, o amplificador HF opera em alta potência, com baixo ganho de tensão e com alta frequência de ganho unitário em relação aos demais OTAs aqui estudados. Esses modos e suas características são descritos na Tabela 1, itens (a) e (b). Os amplificadores Micropotência1, HG e HF foram adaptados de (Eggermont et al., 1996; Gimenez et al., 2003, 2005, 2006) e o OTA Micropotência2 foi adaptado de (Zebulum et. al., 2002).

Faz-se necessário destacar que como o modo Micropotência2 foi inserido neste trabalho para verificar a efetividade do programa AGSPICE na busca de soluções de projeto, pois o ganho de tensão objetivo deste modo é muito maior que o valor possibilitado pelas tecnologia, topologia e restrições de projeto consideradas, o projeto realizado manualmente, baseado nas equações básicas do OTA de primeira ordem, foi realizado somente para os amplificadores Micropotência1, HG e HF.

A faixa de valores de $\mathrm{W}_{x}, \mathrm{~L}_{x}, \mathrm{I}_{P O L}, V_{I N P O L}$ e demais restrições do AGSPICE foram limitados dentro das faixas especificadas como mostra a Tabela 2, a fim de limitar o espaço de busca de soluções do AGSPICE e evitar soluções impraticáveis (como por exemplo, dimensões menores que as dimensões mínimas da tecnologia investigada ou dimensões extremamente grandes).

A faixa de valores assumida pelo parâmetro $\mathrm{I}_{P O L}$ pode ser estimada com base na potência dissipada pelo circuito, com valores em torno de $I_{T O T} / 3$, conforme detalhado na seção 4 anterior. 
Tabela 1: Objetivos desejados para os OTAs intitulados de Micropotência1 e Micropotência2 (a); Alto Ganho (HG) e Alta Frequência (HF) (b).

(a)

\begin{tabular}{|c|c|c|}
\hline Especificações de projeto & Micropotência1 & Micropotência2 \\
\hline $\mathrm{C}_{\mathrm{L}}$ & $10 \mathrm{pF}$ (fixo) & $3 \mathrm{pF}$ (fixo) \\
\hline$V_{D D}$ & 2,5 (V) (fixo) & 3 (V) (fixo) \\
\hline$A_{V_{0}}$ & $44(\mathrm{~dB})$ & $80(\mathrm{~dB})$ \\
\hline $\mathbf{f}_{\mathrm{T}}$ & $0,35(\mathrm{MHz})$ & $0,20(\mathrm{MHz})$ \\
\hline Margem de Fase (PM) & $87^{\circ}$ & $70^{\circ}$ \\
\hline $\mathrm{V}_{\text {OUT }}$ & $\mathrm{V}_{\mathrm{DD}} / 2(1,25 \mathrm{~V})$ & $\mathrm{V}_{\mathrm{DD}} / 2(1,5 \mathrm{~V})$ \\
\hline Potência Dissipada (P $\left.\mathbf{P}_{\mathrm{TOT}}\right)$ & $5(\mu \mathrm{W})$ & $10(\mu \mathrm{W})$ \\
\hline Área & $9500 \mu \mathrm{m}^{2}$ & $5000 \mu \mathrm{m}^{2}$ \\
\hline Tecnologia & $\operatorname{CMOS}(0,35 \mu \mathrm{m})$ & $\operatorname{CMOS}(0,35 \mu \mathrm{m})$ \\
\hline
\end{tabular}

(b)

\begin{tabular}{|l|l|l|}
\hline Especificações de projeto & Alto Ganho (HG) & Alta Frequência (HF) \\
\hline $\mathbf{C}_{\mathbf{L}}$ & $10 \mathrm{pF}$ (fixo) & $10 \mathrm{pF}$ (fixo) \\
\hline $\mathbf{V}_{\mathbf{D D}}$ & $3(\mathrm{~V})$ (fixo) & $4(\mathrm{~V})($ fixo) \\
\hline $\mathbf{A}_{\mathbf{V} \mathbf{0}}$ & $65(\mathrm{~dB})$ & $35(\mathrm{~dB})$ \\
\hline $\mathbf{f}_{\mathbf{T}}$ & $1,8(\mathrm{MHz})$ & $93(\mathrm{MHz})$ \\
\hline Margem de Fase (PM) & $66^{\circ}$ & $55^{\circ}$ \\
\hline $\mathbf{V}_{\text {OUT }}$ & $\mathrm{V}_{\mathrm{DD}} / 2(1,5 \mathrm{~V})$ & $\mathrm{V}_{\mathrm{DD}} / 2(2 \mathrm{~V})$ \\
\hline Potência Dissipada ((P) & $100(\mu \mathrm{W})$ & $29000(\mu \mathrm{W})$ \\
\hline Área & $96000 \mu \mathrm{m}^{2}$ & $82800 \mu \mathrm{m}^{2}$ \\
\hline Tecnologia & $\mathrm{CMOS}(0,35 \mu \mathrm{m})$ & $\mathrm{CMOS}(0,35 \mu \mathrm{m})$ \\
\hline
\end{tabular}

O parâmetro $V_{I N P O L}$ varia de uma faixa de $0,7 \mathrm{~V}$ (aproximadamente a tensão de limiar do transistor nMOSFET) até $V_{D D}$ a fim de garantir que todos os transistores do circuito do OTA operem na região de saturação, especialmente o transistor da fonte de corrente M10 (Allen e Holberg, 2002).

As especificações de projeto e as configurações dos parâmetros do AGSPICE são necessárias para a execução da busca dos objetivos dos OTAs. É importante ressaltar que a maioria dos parâmetros variam de um projeto para o outro. Por exemplo, os valores dos pesos adotados para os objetivos em cada projeto dependem dos objetivos que devem ser priorizados em cada projeto, em detrimento dos demais objetivos. Assim, para os modos Micropotência1 e Micropotência2 devese priorizar a potência dissipada, para o modo HG deve-se priorizar o ganho de tensão e para o modo HF deve-se priorizar a frequência de ganho de tensão unitário. Porém, os valores dos pesos dos objetivos em um determinado projeto foram determinados de forma experimental, de forma a obter o melhor compromisso entre todos os objetivos do projeto. Além disso, existem objetivos que são mais fáceis de serem obtidos que outros. Por exemplo, $P_{A R E A}$ e $P_{M S A T}$ são baixos em todos os projetos (no máximo 10\%), embora sejam obtidas soluções satisfatórias para praticamente todas as soluções obtidas.

A Tabela 3 mostra os valores dos pesos atribuídos a cada objetivo de projeto no programa AGSPICE para realizar o projeto dos OTAs Micropotência1, Micropotência2, HG e HF.
Tabela 2: Restrições de projeto utilizadas no processo de busca do OTA Micropotência1.

\begin{tabular}{|l|l|l|}
\hline Res trição de projeto & Valor & Unidade \\
\hline $\mathbf{W}_{\mathbf{x} \text { min }}$ & 1 & $\mu \mathrm{m}$ \\
\hline $\mathbf{W}_{\mathbf{x m a x}}$ & 1000 & $\mu \mathrm{m}$ \\
\hline $\mathbf{L}_{\mathbf{x} \min }$ & 1 & $\mu \mathrm{m}$ \\
\hline $\mathbf{L}_{\mathbf{x m a x}}$ & 20 & $\mu \mathrm{m}$ \\
\hline $\mathbf{I}_{\text {POLmin }}$ & 0,01 & $\mu \mathrm{A}$ \\
\hline $\mathbf{I}_{\text {POLmax }}$ & 1 & $\mu \mathrm{A}$ \\
\hline $\mathbf{V}_{\text {INPOLmin }}$ & 0,7 & $\mathrm{~V}$ \\
\hline $\mathbf{V}_{\text {INPOLmax }}$ & 2,5 & $\mathrm{~V}$ \\
\hline Faixa de tolerância de $\mathbf{V}_{\text {OUT }}$ & 5 & $\%$ \\
\hline Faixa de tole rância de $\mathbf{P}_{\text {TOT }}$ & 20 & $\%$ \\
\hline
\end{tabular}

Tabela 3: Pesos atribuídos a cada objetivo de projeto para o projeto dos OTAs Micropotência1, Micropotência2, HG e HF.

\begin{tabular}{|c|c|c|c|c|c|}
\hline Parâmetro & Micropotência1 & Micropotência2 & HG & HF & Unidade \\
\hline Peso Eval( $\left.\mathbf{A}_{\mathbf{V} 0}\right)$ & 2 & 25 & 20 & 1 & $\%$ \\
\hline 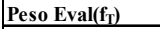 & 26 & 10 & 20 & 31 & $\%$ \\
\hline Peso Eval(PM) & 15 & 30 & 30 & 29 & $\%$ \\
\hline Peso Eval(V Vut $_{\text {OUT }}$ & 25 & 10 & 15 & 16 & $\%$ \\
\hline Peso Eval(P $\left(\mathrm{P}_{\text {TOT }}\right)$ & 24 & 10 & 10 & 15 & $\%$ \\
\hline Peso Eval(Area) & 5 & 10 & 0 & 0 & $\%$ \\
\hline Peso Eval(M M $\left._{\text {SAT }}\right)$ & 3 & 5 & 5 & 8 & $\%$ \\
\hline
\end{tabular}

O valor do parâmetro sigma das curvas de avaliação gaussianas $(\sigma)$ foi ajustado com o valor de 0,3 no AGSPICE em todos os projetos realizados.

O tamanho da população e o número total de indivíduos são parâmetros de entrada do AGSPICE ajustados também experimentalmente. Inicialmente havia sido adotado uma população de 100 indivíduos e um número total de 100.000 indivíduos. Então o tamanho da população foi reduzido para 75 indivíduos e um total de 75.000 indivíduos. Logo após, o tamanho da população foi reduzido para 50 indivíduos e um total de 50.000 indivíduos, sempre mantendo o número total de 1.000 gerações e 20 rodadas. Dessa forma, o tamanho da população foi sendo gradativamente reduzido até que foi adotado um número reduzido de 10 indivíduos e um total de 10.000 indivíduos em todos os experimentos dos OTAs projetados, pois foi observado, durante o procedimento de ajuste do tamanho da população, que a população de 10 indivíduos permitiu ao AGSPICE produzir soluções com valores de avaliação tão altos quanto a população de 100 indivíduos. Então optou-se por adotar uma população de 10 indivíduos, de forma a priorizar a análise do circuito em relação ao tempo de simulação.

De forma a obter 10 soluções que atendam todos os requisitos mencionados na Tabela 1 , com um desvio máximo de $20 \%$, foram realizadas de 20 a 40 rodadas, dependendo da dificuldade de obtenção das soluções do OTA projetado. Adicionalmente, o tempo do processo de busca do AGSPICE por rodada, ou seja, o tempo total do processo de busca normalizado em função do número de rodadas, necessário para 
obtenção das soluções de cada modo de operação analisado, é mostrado na Tabela 4. Nota-se que o tempo de busca é factível e promissor, pois utilizou-se uma máquina de configuração básica e arquitetura IBM-PC, conforme descrito no início desta seção.

Tabela 4: Tempo do processo de busca do AGSPICE por rodada para cada modo de operação.

\begin{tabular}{|c|c|}
\hline Modo & Tempo de busca do AGSPICE por rodada \\
\hline Micropotência1 & 1 hora e 3 minutos \\
\hline Micropotência2 & 43 minutos \\
\hline HG & 1 hora e 1 minuto \\
\hline HF & 34 minutos \\
\hline
\end{tabular}

\section{RESULTADOS}

Os gráficos de barras das Figuras 8, 9 e 10 mostram as diferenças dos resultados de desempenho obtidos pelo AGSPICE e pelo projeto manual em relação aos objetivos de projeto estabelecidos. Os resultados apresentados pelo AGSPICE são aqueles que alcançaram o melhor desempenho dentre todas as rodadas.

No caso do modo Micropotência1, o AGSPICE obteve, em relação ao projeto manual, um menor $A_{V 0}$, uma maior $f_{T}$, uma menor margem de fase, um pior $V_{O U T}$, pois a diferença em relação a $V_{D D} / 2$ é maior e uma área significativamente maior. Porém o projeto manual obteve potência dissipada muito acima do valor desejado, mais de $450 \%$, enquanto que o AGSPICE obteve potência dissipada apenas 2,6\% acima do valor desejado [Figuras 8(a) e 8(b)].

No caso do modo HG, o AGSPICE obteve, em relação ao projeto manual, um menor $A_{V 0}$, uma maior $f_{T}$, uma maior margem de fase, similar valor para a tensão de saída DC, uma maior área e uma maior potência dissipada. Como o projeto manual e o AGSPICE obtiveram exatamente o valor desejado para $V_{O U T}\left(V_{D D} / 2\right)$, a diferença em relação ao valor objetivo é igual a zero e assim estas barras não aparecem no gráfico da Figura 9(a). Nesse caso, a grande dificuldade do projeto manual é a obtenção de uma margem de fase adequada, uma vez que a margem de fase do OTA HG no projeto manual resultou mais de $50 \%$ abaixo do valor desejado, enquanto que o AGSPICE obteve uma margem de fase muito próxima do valor objetivo, nesse caso, um valor apenas $0,76 \%$ acima do valor desejado [Figuras 9(a) e 9(b)].

No caso do modo HF, o AGSPICE obteve, em relação ao projeto manual, um maior $A_{V 0}$, uma maior $f_{T}$, uma menor margem de fase, um melhor $V_{O U T}$, pois o AGSPICE obteve exatamente o valor desejado, ou seja, $V_{D D} / 2$, uma maior área e uma menor potência dissipada. Como no caso do modo Micropotência1, o projeto manual obteve potência dissipada

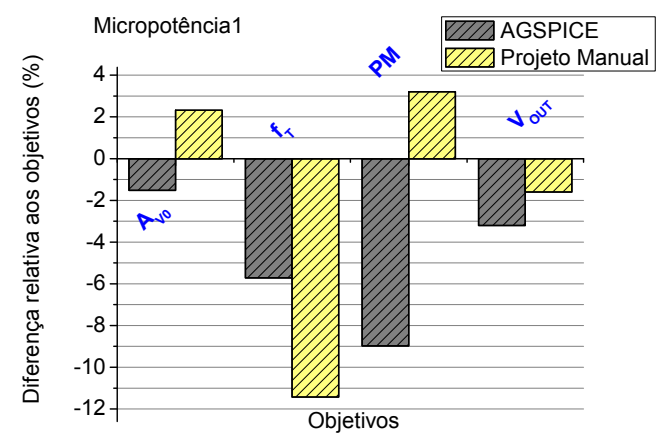

(a)

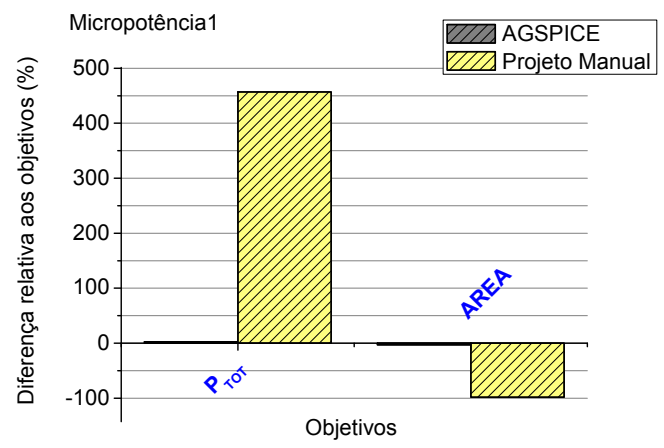

(b)

Figura 8: Comparação dos objetivos $A_{V 0}, f_{T}, \mathrm{PM}$ e $V_{O U T}$ (a); $P_{T O T}$ e AREA (b) para o modo Micropotência1.

muito acima do valor desejado, quase $150 \%$, enquanto que o AGSPICE obteve potência dissipada apenas 1,3\% acima do valor desejado [Figuras 10(a) e 10(b)].

No caso do AGSPICE, com exceção da AREA, cujo peso é igual a zero, a maior diferença é o valor de $A_{V 0}$, que resultou $8,86 \%$ superior ao respectivo objetivo, pois o peso adotado foi de apenas $1 \%$.

O resultado mais importante observado nessas comparações é poder verificar que o AGSPICE conseguiu obter resultados sempre mais próximos dos objetivos de projeto em relação aos resultados encontrados pelo projeto manual. Adicionalmente, no projeto desenvolvido manualmente existe uma grande dificuldade de se obter resultados satisfatórios para vários objetivos de projeto ao mesmo tempo, pois quando uma determinada solução manual atende uma determinada especificação, deixa de atender adequadamente uma determinada outra especificação, ao contrário do AGSPICE que, na maioria dos casos, procura atender todas as especificações ao mesmo tempo de forma ponderada.

No caso do projeto manual, observou-se que a grande dificuldade é o compromisso entre a potência dissipada e a resposta em frequência, uma vez que para obter o valor de $f_{T}$ 


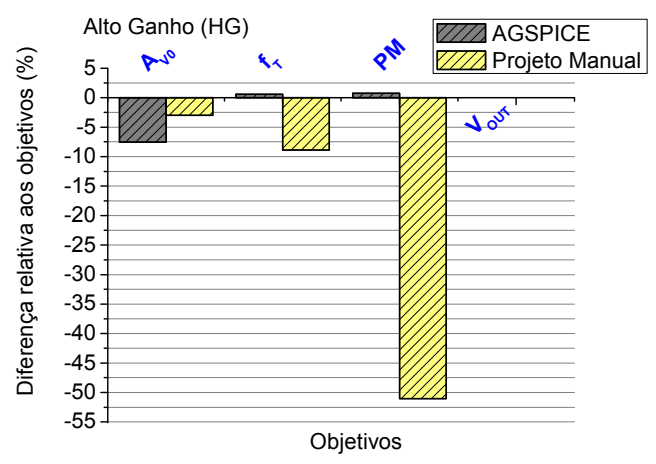

(a)

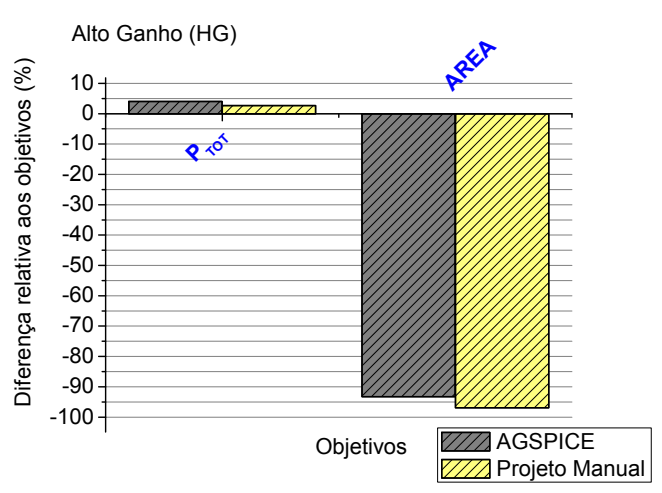

(b)

Figura 9: Comparação dos objetivos $A_{V 0}, f_{T}$, PM e $V_{O U T}$ (a); $\mathrm{P}_{T O T}$ e AREA (b) para o modo HG.

desejado para os modos Micropotêncial e HF houve necessidade de um aumento muito grande no consumo de potência. Portanto, devido ao grande número de variáveis envolvidas, tais como dimensões W e L dos transistores, corrente de polarização $\left(\mathrm{I}_{P O L}\right)$ e tensão de entrada em modo comum de polarização $\left(V_{I N P O L}\right)$, encontrar soluções satisfatórias para um grande número de objetivos, na grande maioria das vezes, exige muito tempo de simulação e grande experiência do projetista.

O erro máximo encontrado entre os valores desejados para os objetivos de projeto e os resultados obtidos pelo AGSPICE para os OTAs Micropotência1, Micropotência2, HG e HF não ultrapassou 9,0\%, com exceção do objetivo AREA, enquanto que o processo manual apresentou quase sempre valores superiores a $20 \%$ de erro. Isso mostra que o processo automático alcançou melhores resultados em relação àqueles obtidos pelo processo manual, baseado nas equações de primeira ordem do OTA e, importantíssimo enfatizar, em conhecimento de um projetista iniciante.

A Tabela 5 apresenta os valores recomendados para $\mathrm{I}_{P O L} \mathrm{e}$ $V_{I N P O L}$ em função do modo de operação desejado, onde a

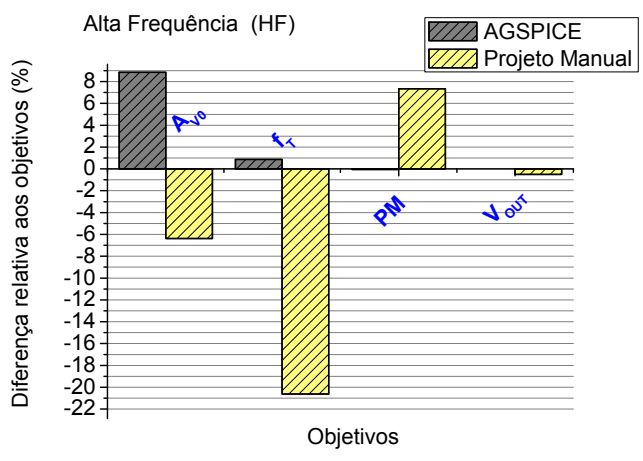

(a) (a)

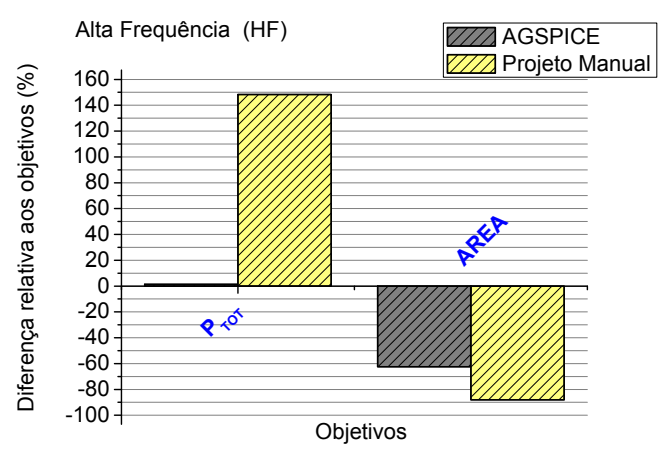

(b) (a)

Figura 10: Comparação dos objetivos $A_{V 0}, f_{T}$, PM e $V_{O U T}$ (a); $\mathrm{P}_{\text {TOт }}$ e AREA (b) para o modo HF.

melhor solução em cada modo de operação está identificada pela coluna Melhor, a coluna $\mu_{S}$ apresenta o valor médio e a coluna $\sigma_{S}$ apresenta o desvio padrão em porcentagem em relação à média das 10 melhores soluções apresentadas pelo AGSPICE ao final do processo de busca.

Tabela 5: Corrente de polarização $\left(\mathrm{I}_{P O L}\right)$ e tensão de polarização $\left(V_{I N P O L}\right)$ do circuito, em função do modo de operação desejado.

\begin{tabular}{|c|c|c|c|c|c|c|c|c|c|c|}
\hline \multirow{2}{*}{ Modo de operação } & \multicolumn{3}{|c|}{$\mathbf{P}_{\text {Tот }}(\mu \mathrm{W})$} & \multicolumn{3}{|c|}{$\mathrm{I}_{\mathrm{POL}}(\boldsymbol{\mu} \mathrm{A})$} & \multicolumn{3}{|c|}{$\mathrm{V}_{\text {INPOL }}(\mathrm{V})$} & \multirow{2}{*}{$V_{D D}(V)$} \\
\hline & Melhor & $\mu_{\mathrm{s}}$ & $\sigma_{\mathrm{S}}(\%)$ & Melhor & $\mu_{\mathrm{s}}$ & $\sigma_{\mathrm{S}}(\%)$ & Melhor & $\mu_{\mathrm{s}}$ & $\sigma_{\mathrm{S}}(\%)$ & \\
\hline Micropotência1 & 5,13 & 5,50 & 4,41 & 0,06 & 0,16 & 92,41 & \begin{tabular}{|l|}
1,48 \\
\end{tabular} & 1,30 & 28,17 & 2,50 \\
\hline Micropotência2 & 9,66 & 10,16 & 5,76 & 0,91 & 0,82 & 26,11 & 1,09 & 2,09 & 25,81 & 3,00 \\
\hline HG & 104,04 & 102,58 & 3,73 & 4,05 & 9,08 & 35,32 & 2,03 & 1,44 & 41,86 & 3,00 \\
\hline HF & 29376,56 & 29349,98 & 1,88 & 2409,87 & 2047,29 & 29,76 & 2,91 & 2,75 & 17,52 & 4,00 \\
\hline
\end{tabular}

O valor da corrente de polarização $\left(\mathrm{I}_{P O L}\right)$ está diretamente ligado ao consumo de potência do circuito. Assim, os valores recomendados para este parâmetro devem estar em concordância com os valores de potência estabelecidos como objetivo.

O valor do parâmetro $V_{I N P O L}$ (tensão de entrada em modo comum) deve ser adotado de forma que todos os transistores 
do circuito operem na região de saturação, especialmente o transistor M10 da fonte de corrente. Dessa forma, podem ser adotados valores menores, maiores ou em torno de $V_{D D} / 2$ para este parâmetro, de forma a garantir esta condição, com o objetivo de obter os valores de $A_{V 0}$ e a excursão do sinal de saída desejados (Allen e Holberg, 2002).

Verifica-se que as especificações de projeto podem ser atendidas com pequena dispersão, tal como os valores de $P_{T O T}$ destacados em vermelho na Tabela 5. Porém, os valores altos da dispersão de $I_{P O L}$ e $V_{I N P O L}$ indicam que é possível uma grande variedade de soluções que atendam satisfatoriamente todos os objetivos de projeto.

A Tabela 6 mostra as dimensões dos transistores dos OTAs em função do modo de operação desejado, onde a melhor solução em cada modo de operação está identificada pela coluna Melhor, a coluna $\mu_{S}$ apresenta o valor médio e a coluna $\sigma_{S}$ apresenta o desvio padrão em porcentagem em relação à média das 10 melhores soluções apresentadas pelo AGSPICE.

Devido à elevada dispersão das dimensões $\mathrm{W}$ e $\mathrm{L}$ de todos os transistores do circuito do OTA, observada em todos os modos de operação, conclui-se que existem diversas possibilidades para o dimensionamento dos transistores do OTA. Porém, a Tabela 6 mostra que o dimensionamento do par nMOSFET de saída M7-M8, assim como o dimensionamento do comprimento de canal do par pMOSFET de saída M5-M6 são críticos, pois apresentam desvios menores em relação aos demais transistores do circuito. Os valores críticos estão destacados em vermelho na Tabela 6 .

Tabela 6: Dimensões dos transistores dos OTAs obtidas pelo AGSPICE para os modos Micropotência1 e Micropotência2 (a); $H G$ e HF (b).

(a)

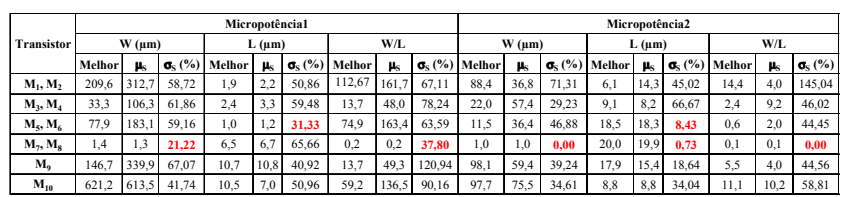

(b)

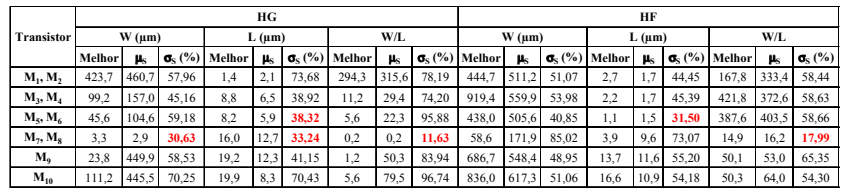

\subsection{Respostas em Frequência dos OTAs}

A Figura 11 apresenta um exemplo do diagrama de Bode (curvas do ganho de tensão e de fase em função da frequên- cia) para o caso do OTA intitulado de HF, obtido através do simulador SPICE, com a finalidade de validar o comportamento da resposta em frequência dos amplificadores projetados pelo AGSPICE de forma automática.

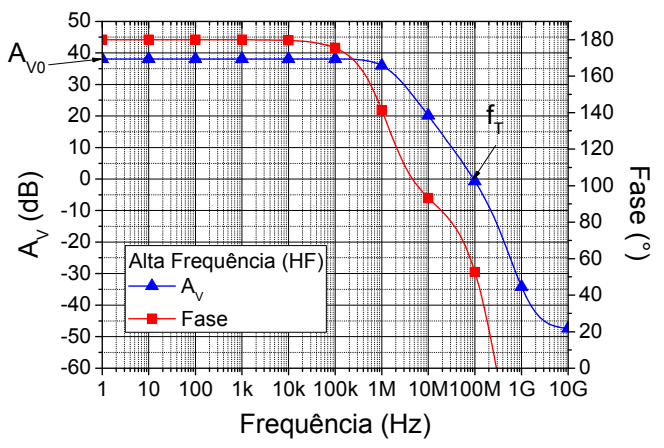

Figura 11: Diagrama de Bode do OTA HF obtido através do AGSPICE.

O comportamento das curvas $A_{V}$ e fase em função da frequência de todos os OTAs estudados apresentam aspectos e comportamentos similares àqueles encontrados na literatura (Eggermont et al., 1996; Gimenez et al., 2003, 2005, 2006). Além disso, as curvas de ganho de tensão apresentam uma queda de $20 \mathrm{~dB} /$ década. Conforme mencionado na literatura, esta característica é fundamental para garantir margem de fase positiva e operação estável dos OTAs projetados.

\subsection{Avaliação e mapeamento das solu- ções}

A Figura 12 mostra as curvas de avaliação média dos objetivos em função do número de gerações, para cada modo de operação desejado. O valor médio é calculado para as 10 melhores soluções apresentadas pelo AGSPICE, selecionadas pelo critério do maior valor de avaliação. Note que a função de avaliação consegue atingir praticamente na sua plenitude os objetivos de projeto para os OTAs Micropotência1, HG e HF, com valores de avaliação próximos de 100 e satisfatoriamente os objetivos com relação ao OTA Micropotência2 $(90,63)$, devido à limitação inerente a essa arquitetura de circuito que está de acordo com as dificuldades encontradas durante o projeto manual desse tipo de OTA.

A Figura 13 apresenta um exemplo do mapeamento do ganho de tensão $\mathrm{DC}$ em malha aberta $\left(A_{V 0}\right)$ em função do número de gerações de todos os OTAs estudados, o qual representa uma das características que se refere à resposta em frequência. Pode-se reparar também que o AGSPICE foi capaz de encontrar as soluções para as especificações de $A_{V 0}$ de todos os OTAs analisados com erro máximo em torno de $8,9 \%$ em relação aos valores desejados [ver Tabelas 1(a) e 1(b)], 


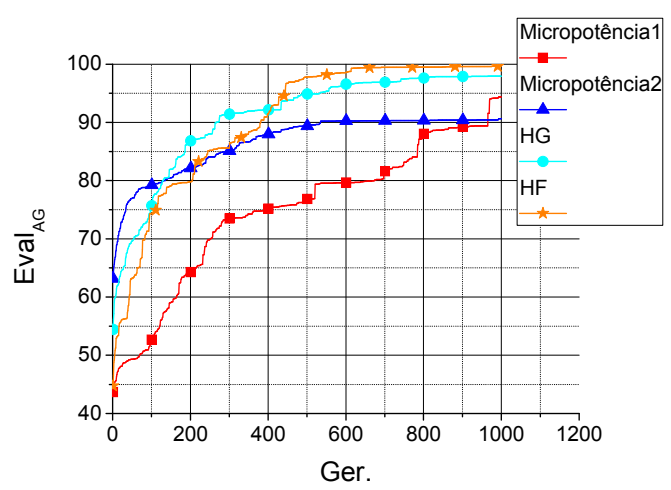

Figura 12: item Curvas da função de avaliação dos objetivos em função do número de gerações do processo AG dos OTAs analisados.

com exceção do OTA Micropotência2. Neste caso, o valor de $A_{V 0}$ do OTA HF atinge um valor de $38,1 \mathrm{~dB}$, valor levemente superior ao valor objetivo de $35 \mathrm{~dB}$. No caso do OTA Micropotência2, o valor de $A_{V 0}$ obtido atinge $61,38 \mathrm{~dB}$, valor $23,3 \%$ inferior ao valor desejado de $80 \mathrm{~dB}$. Neste caso, as equações básicas do circuito mostram que, dada a tecnologia utilizada, a topologia do OTA e as restrições de projeto adotadas, o valor máximo para o valor de $A_{V 0}$ se situa em torno do valor encontrado pelo AGSPICE.

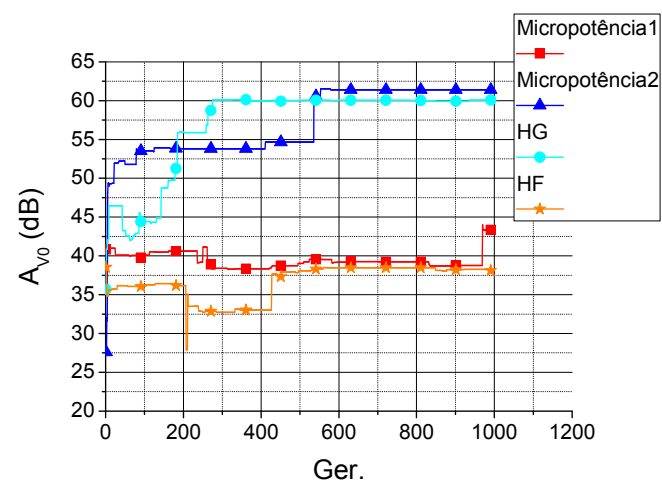

Figura 13: Curvas do ganho de tensão em malha aberta $\left(A_{V 0}\right)$ em função do número de gerações.

Por meio dessa ferramenta de auxílio ao projeto de circuitos analógicos é possível também mapear as dimensões (W e L) e o regime de inversão de cada transistor que compõe cada um dos OTAs estudados. A Tabela 7 resume os regimes de inversão do canal dos transistores do circuito, em função do modo de operação desses OTAs. Alguns dos resultados obtidos para os regimes de inversão dos transistores dos OTAs estão de acordo com a literatura (Eggermont et al., 1996; Gimenez et al., 2003, 2005, 2006; Silveira et al., 1996), como por exemplo a tendência do par diferencial do modo HF ser polarizado próximo à região de inversão forte e próximo à região de inversão fraca no modo Micropotência1. Porém os resultados dos regimes de inversão dos demais transistores (espelhos e corrente pMOSFETs e nMOSFETs) ainda não são reportados na literatura e, devido à dificuldade do projeto manual, estes resultados dificilmente poderiam ser obtidos pelo projeto tradicional (manual).

Tabela 7: Regimes de inversão do canal dos transistores, em função do modo de operação desejado.

\begin{tabular}{|c|c|c|c|c|}
\hline \multirow{2}{*}{ Modo de operação } & \multicolumn{4}{|c|}{ Regimes de inversão do canal dos transistores } \\
\cline { 2 - 6 } & $\begin{array}{c}\text { Par diferencial } \\
\text { M1-M2 }\end{array}$ & $\begin{array}{c}\text { Espelho nMOSFET } \\
\text { M7-M8 }\end{array}$ & $\begin{array}{c}\text { Espelho da fonte de } \\
\text { corrente M9-M10 }\end{array}$ & $\begin{array}{c}\text { Espelhos } \\
\text { pMOSFETs } \\
\text { M3-M5 e M4-M6 }\end{array}$ \\
\hline Micropotência1 & $\begin{array}{c}\text { Regão de inversão } \\
\text { Fraca }\end{array}$ & $\begin{array}{c}\text { Região de inversão } \\
\text { Moderada próxima } \\
\text { do Centro para } \\
\text { próxima da Forte }\end{array}$ & $\begin{array}{c}\text { Região de inversão } \\
\text { Fraca }\end{array}$ & $\begin{array}{c}\text { Região de inversão } \\
\text { Fraca para próxima } \\
\text { da Moderada }\end{array}$ \\
\hline Micropotência2 & $\begin{array}{c}\text { Início para o centro } \\
\text { da região de } \\
\text { inversão Moderada }\end{array}$ & $\begin{array}{c}\text { Regão de inversão } \\
\text { Moderada próxima } \\
\text { do Centro para } \\
\text { próxima da Forte }\end{array}$ & $\begin{array}{c}\text { Região de inversão } \\
\text { Moderada próxima } \\
\text { da Fraca para } \\
\text { próxima do Centro }\end{array}$ & $\begin{array}{c}\text { Região de inversão } \\
\text { Moderada próxima } \\
\text { da Fraca para o } \\
\text { Centro }\end{array}$ \\
\hline HG & $\begin{array}{c}\text { Final da região de } \\
\text { inversão Fraca } \\
\text { para início da } \\
\text { Moderada }\end{array}$ & $\begin{array}{c}\text { Final da região de } \\
\text { inversão Moderada } \\
\text { para início da Forte }\end{array}$ & $\begin{array}{c}\text { Centro da região de } \\
\text { inversão Moderada } \\
\text { para próxima da } \\
\text { Forte }\end{array}$ & $\begin{array}{c}\text { Centro da Regão } \\
\text { de inversão } \\
\text { Moderada }\end{array}$ \\
\hline HF & $\begin{array}{c}\text { Regãa de inversão } \\
\text { Moderada próxima } \\
\text { do Centro para } \\
\text { próxima da Forte }\end{array}$ & $\begin{array}{c}\text { Região de inversão } \\
\text { Forte }\end{array}$ & $\begin{array}{c}\text { Região de inversão } \\
\text { Forte próxima da } \\
\text { Moderada }\end{array}$ & $\begin{array}{c}\text { Final da região de } \\
\text { inversão Moderada } \\
\text { para início da Forte }\end{array}$ \\
\hline
\end{tabular}

\section{DISCUSSÃO}

Verifica-se, pela Tabela 6, que o modo de operação Micropotência1 tende a apresentar os valores de $\mathrm{L}_{3,4}$ e $\mathrm{L}_{5,6}$ menores que os demais modos analisados e apresentam os valores das razões de aspecto $(W / L)_{3,4}$ e $(W / L)_{5,6}$ relativamente altos em comparação com os modos Micropotência2 e HG. Estes fatores estão relacionados à obtenção de valores baixos para a área dos transistores M4 e M6, assim como a polarização dos espelhos pMOSFETs na região de inversão fraca, especialmente o transistor M4. A redução dessas capacitâncias intrínsecas do circuito do OTA, assim como a elevação do valor da transcondutância do transistor M4 $\left(\mathrm{g}_{m 4}\right)$ permitem um significativo aumento da margem de fase e podem levar à redução do valor da AREA.

Pela Tabela 6, pode-se observar também que, nos modos de operação que apresentam os maiores valores de $A_{V 0}$ (OTAs Micropotência2 e HG) os valores para os comprimentos de canal dos transistores de saída (L6 e L8), tanto das soluções médias como das melhores soluções, são maiores do que para os modos de operação que apresentam menores valores de $A_{V 0}$ (OTAs Micropotência1 e HF). Dessa forma, deve-se adotar os comprimentos de canal dos transistores de saída (L6 e L8) do OTA tão altos quanto possível, com o objetivo de obter alto ganho de tensão $\left(A_{V 0}\right)$, pois quanto maiores são os comprimentos de canal dos transistores de saída do OTA, 
maiores os valores correspondentes das resistências de saída e das tensões Early ( $V_{A 6}$ e $\left.V_{A 8}\right)$.

Pode-se notar também que o modo HG tende a apresentar o valor da largura de canal do par diferencial $\left(\mathrm{W}_{1,2}\right)$ e a razão de aspecto $(W / L)_{1,2}$ significativamente maiores que os modos Micropotência1 e Micropotência2, devido à necessidade de polarização do par diferencial na região de inversão fraca, com o objetivo de alcançar alto ganho de tensão $\left(A_{V 0}\right)$, embora o valor do ganho objetivo do modo HG (65 dB) seja menor que o valor do ganho objetivo do modo Micropotência2 $(80 \mathrm{~dB})$. Isto ocorre porque além da necessidade de alcançar alto ganho de tensão, que requer a polarização do par diferencial na região de inversão fraca, também existe a necessidade de obter um valor moderado para a frequência de operação do circuito do OTA HG, significativamente maior que no modo Micropotência2, o que implica em maior potência dissipada e maior corrente do par diferencial $\left(\mathrm{I}_{D S 1,2}\right)$, em relação ao modo Micropotência2. Dessa forma, a corrente normalizada do par diferencial $\left[\left(\mathrm{I}_{D S} /(\mathrm{W} / \mathrm{L})\right)_{1,2}\right]$ na região de inversão fraca requer alto valor para $\mathrm{W}_{1,2} \mathrm{e}(W / L)_{1,2}$, devido ao alto valor de $\mathrm{I}_{D S 1,2}$.

No modo de operação $\mathrm{HG}$, verifica-se também que o valor do comprimento de canal do par diferencial $\mathrm{L}_{1,2}$ tende a apresentar dimensões próximas do valor mínimo estabelecido para o processo de busca do AGSPICE, sendo o valor médio igual a $2,1 \mu \mathrm{m}$ e a dimensão mínima do comprimento de canal limitada em 1,0 $\mu \mathrm{m}$. Utilizar valores baixos de comprimento de canal para o par diferencial $\left(\mathrm{L}_{1,2}\right)$, em vez de utilizar valores altos para a largura de canal $\left(\mathrm{W}_{1,2}\right)$, com o objetivo de obter valores altos para a razão de aspecto $\left[(W / L)_{1,2}\right]$, permite aumentar a margem de fase, devido à redução da área e das capacitâncias intrínsecas associadas ao par diferencial.

Como no modo HF o valor do ganho de tensão é baixo, os valores de L6 e L8 não necessitam ser elevados. Assim, os valores de L6 e L8 tendem a ser menores em relação aos outros OTAs e como o par M7-M8 tende a ser polarizado em direção à região de inversão forte, apresenta valores baixos para o parâmetro $(W / L)_{7,8}$. Os valores baixos de $\mathrm{L}_{5,6}$ e $\mathrm{L}_{7,8}$ podem ser um compromisso com a margem de fase, pois a redução de área dos transistores M5, M7 e M8 permitem reduzir a capacitância interna do nó 2 , conforme mostra a Figura 1 anterior do circuito do OTA, possibilitando aumentar a margem de fase.

O mapeamento realizado para o modo HG mostra que é possível aumentar levemente o valor de $f_{T}$ sem aumentar o valor da corrente do par diferencial, $I_{D S 1,2}$, e sem aumentar o consumo de potência $\left(\mathrm{P}_{T O T}\right)$. Neste caso, a polarização do par diferencial na região de inversão fraca permite a obtenção de valores altos para $\left(g_{m} / I_{D S}\right)_{1,2}$, elevando o valor de $f_{T}$, conforme mostra a equação (4) anterior de primeira ordem do OTA.

O mapeamento realizado para o modo HF mostra que a polarização do par diferencial da região de inversão forte para a região de inversão moderada, além do ajuste adequado do fator de ganho dos espelhos de corrente pMOSFETs $\left(B_{4,6}\right)$, de 0,59 a 1,9 neste caso, são fundamentais para a obtenção do valor de $f_{T}$ desejado.

Na Tabela 6, nota-se que as melhores soluções dos modos HG e HF para os valores do comprimento de canal L10 do transistor de saída da fonte de corrente do par diferencial (M10) são altos, ou seja, próximos de $20 \mu \mathrm{m}$. Este resultado é muito conveniente, pois quanto maior o valor de L10, menor a variação da corrente de saída $\left(\mathrm{I}_{O}\right)$, com relação à tensão entre dreno e fonte $\left(V_{D S}\right)$ do transistor M10.

O mapeamento das variáveis de entrada mostra que o espelho de corrente nMOSFET formado pelos transistores M7 e M8 deve operar em direção à região de inversão forte, com o objetivo de alcançar o valor de $V_{O U T}$ estabelecido como objetivo de projeto. Dessa forma, todos os modos analisados apresentam baixos valores para a largura de canal do par M7-M8 $\left(W_{7,8}\right)$, com o objetivo de obter baixos valores para as razões de aspecto $(W / L)_{7,8}$, de forma a alcançar o valor de $V_{O U T}$ próximo de $V_{D D} / 2$. Este processo induz o par M7M8 ser polarizado em direção à região de inversão forte e pode contribuir para a redução da AREA.

\section{CONCLUSÃO}

Este trabalho teve como objetivo principal desenvolver um sistema evolucionário de otimização baseado em Algoritmos Genéticos que, integrado computacionalmente ao simulador de circuitos SPICE, permitiu uma melhor compreensão do comportamento das condições de polarização $\left(\mathrm{I}_{P O L}\right.$, $\left.V_{I N P O L}\right)$, dos regimes de inversão $\left[\mathrm{I}_{D S} /(\mathrm{W} / \mathrm{L})\right]$ e, consequentemente, das dimensões dos transistores (W, L, e W/L) para diferentes modos de operação do OTA CMOS de um único estágio e uma única saída.

O tempo de desenvolvimento do projeto dos OTAs pelo sistema AGSPICE proposto se mostrou factível e promissor. Portanto, acredita-se que o AGSPICE possa ser uma ferramenta útil para reduzir o tempo e o custo do projeto de circuitos integrados analógicos, principalmente para projetistas iniciantes. Adicionalmente, espera-se que o AGSPICE possa permitir ao projetista um melhor entendimento sobre o comportamento do OTA e como as regiões de inversão e as dimensões dos transistores de cada bloco do amplificador se comportam para um determinado objetivo de projeto. 
Como trabalhos futuros, vislumbram-se as seguintes possibilidades de investigação científica: (1) Desenvolvimento dos leiautes dos dispositivos desenvolvidos e simulados pelo AGSPICE para posterior medição e validação em bancada (por exemplo, por meio do Programa Educacional MOSIS); (2) Inclusão de outros objetivos de projeto na função de avaliação do AGSPICE, tais como o slew rate e a razão de rejeição em modo comum (CMRR); (3) Estudo sobre novas formas de avaliação do sistema AGSPICE que não estejam baseadas em uma função de agregação de objetivos, mas sim em análises de superfícies de Pareto com múltiplos objetivos, tais como o procedimento NSGA ("Non-dominated Sorting Genetic Algorithm") (Deb, 2008); e (4) Implementação de novas topologias de OTAs CMOS e outros circuitos que também fazem parte dos blocos básicos de CIs analógicos.

\section{REFERÊNCIA BIBLIOGRÁFICA}

Allen, P. E.; Holberg, D. R. "CMOS Analog Circuit Design". New York: Oxford University Press, 2002. 775p.

Ando, S.; Iba, H. "Analog Circuit Design with a Variable Length Cromossome". IEEE Proceeding of the 2000 Congress on Evolutionary Computation, USA, p 9941001, 2000.

Barros, M.; Neves, G.; Guilherme, J.; Horta, N. "An Evolutionary Optimization Kernel with adaptative Parameters Applied to Analog Circuit Design". International Symposium on Signals, Circuits and Systems, 2005 (ISSCS 2005), pp. 545-548 v.2 July 14-15, 2005.

Coello, Carlos A.; Lamont, Gary B.; Veldhuizen, David A. Van. "Evolutionary Algorithms for Solving MultiObjective Problems". Editora: SPRINGER VERLAG NY, 2007.

Cortes, F. D. R. P. "Modelagem e Projeto de Módulos Amplificadores e Comparadores em Tecnologia CMOS 0,35 $\mu$ m". 2003, 124 f. Dissertação (Mestrado em Ciência da Computação) - UNIVERSIDADE FEDERAL DO RIO GRANDE DO SUL, Porto Alegre.

Deb, K. "Multi-Objective Optimization using Evolutionary Algorithms". Editora: Wiley, 2008.

Eggermont, J. P.; Ceuster, D. D.; Flandre, D.; Gentinne, B.; Jespers, P. G. A.; Colinge, J. P. "Design of SOI CMOS Operational Amplifiers for Applications up to $300^{\circ} \mathrm{C}$ ". In: IEEE JOURNAL OF SOLID-STATE CIRCUITS, VOL. 31, N. 2, FEBRUARY 1996.

Gimenez, S. P.; Pavanello, M.; Martino, J.; Flandre, D. "Gain improvement in operational transconductance amplifiers using Graded-Channel SOI nMOSFETS". Microelectronics (Luton) (Cessou em 1978. Cont.
ISSN 0959-8324 Microelectronics Journal), Oxford, United Kingdom, v. 37, n. 1, p. 31-37, 2006.

Gimenez, S. P.; Pavanello, M. A.; Martino, J. A.; Flandre, D. "Implementation of High Performance Operational Transconductance Amplifiers using GradedChannel SOI nMOSFETs". In: 12th International Symposium on Silicon-on-Insulator Technology and Devices, 2005, Quebec - Canada. Silicon-on-Insulator Technology and Devices XII - Proceedings of the International Symposium. Pennington, NJ, USA : Electrochemical Society, Inc., 2005. v. 2005-3. p. 69-74.

Gimenez, S. P.; Pavanello, M. A.; Martino, J. A. "Design of Operational Transconductance Amplifiers with Improved Gain by Using Graded-Channel SOI nMOSFETs". In: 16th Symposium on Integrated Circuits and System Design, SBCCI 2003, São Paulo. SBCCI-2003 - Chip in Sampa. CA - USA : IEEE Computer Society, 2003. v. 1. p. 26-31.

Goldberg, D. E. "Genetic Algorithms in Search, Optimization, and Machine Learning". 27 ed., EUA: Editora Adison Wesley Longman, Inc., 1989.

McConaghy, T.; Palmers, P; Gao, P.; Steyaert, M.; Gielen, G. "Variation-Aware Analog Structural Synthesis: A Computational Intelligence Approach". Editora: Springer, 2009.

Microsoft Visual Studio 2008 Version 9.0.21022.8 RTM. Microsoft .NET Framework Version 3.5 SP1.

Parâmetros SPICE BSIM3 versão 3.1. Data: 22 de Dezembro de 2009, lote: T99J. Disponível em: http://www.mosis.com/cgibin/cgiwrap/umosis/swp/params/ami-c5/t99jparams.txt .

Rego, T. T. do; Gimenez, S. P. and Thomaz, C. E. "Mapping and understanding the multivariate and multi-objective optimization behavior of a SOI CMOS OTA using genetic algorithms". In proceedings of the 9th Students Forum on Microelectronic SForum'09, 4pp., Natal, Rio Grande do Norte, Brazil, August 31st - September 3rd 2009.

Santini, C. "Desenvolvimento de uma plataforma reconfigurável analógica para a evolução intrínseca de circuitos". $118 \mathrm{f}$. Thesis (Masters in Electrical Engineering) - Electrical Engineering Department - Pontifícia Universidade Católica do Rio de Janeiro, Rio de Janeiro, 2001.

Silveira, F.; Flandre, D. and Jespers, P. G. A. " $\mathrm{A}_{m} / \mathrm{I}_{D}$ Based Methodology for the Design of CMOS Analog Circuits and Its Application to the Synthesis of a Siliconon-Insulator Micropower OTA". IEEE JOURNAL OF 
SOLID-STATE CIRCUITS, VOL. 31, N. 9, SEPTEMBER 1996.

Spice Opus (c) version 2.31. Revision: 175. Circuit Simulator. Date Built: Oct 14 2009. University of Ljubljana Slovenia. Faculty of Electrical Engineering. Group for Computer Aided Design. http://www.spiceopus.sihttp://www.spiceopus.si.

Tuma, T.; Búrmen, Á. "Circuit Simulation with SPICE OPUS Theory and Practice". Birkhäuser Boston, 2009.

Wójcikowski, M.; Jacek, G.; Bialko, M. "System for Optimization of Electronic Circuit Using Genetic Algorithm". 3rd IEEE international conference on electronics, circuits and systems (ICECS'96), Rodos, Greece, pp. 247-250, October 13-16, 1996.

Zebulum, R. S.; Pacheco, M. A. C.; Vellasco, M. M. B. R. "Evolutionary Electronics: Automatic Design of Electronic Circuits and Systems by Genetic Algorithms". EUA: Editora CRC, 2002. 